NBER WORKING PAPER SERIES

WORLD REAL INTEREST RATES

Robert J. Barro

Xavier Sala 1 Martin

Working Paper No. 3317

NATIONAL BUREAU OF ECONOMIC RESEARCH

1050 Massachusetts Avenue

Cambridge, MA 02138

April 1990

\footnotetext{
We are grateful for comments from Jason Barro, 01ivier Blanchard, B111 Brainard, Bob Lucas, Greg Mankiw, Larry Summers, and Andrew Warner. We appreciate the research assistance of Casey Mulligan. The statistical analysis in this paper was carried out with Micro TSP. This paper is part of NBER's research programs in Economic Fluctuations and Growth. Any opinions expressed are those of the authors and not those of the National Bureau of Economic Research.
} 
NBER Working Paper \#3317

Apri1 1990

\title{
WORLD REAL INTEREST RATES
}

\begin{abstract}
We think of the expected real interest rate for ten OECD countries (our counterpart of the world economy) as determined by the equation of aggregate investment demand to aggregate desired saving. Stock-market returns isolate shifts to investment demand, and changes in oll prices, monetary growth, and fiscal variables isolate shifts to desired saving. We estimated the reduced form for GDP-weighted world averages of the expected short-term real interest rate and the investment ratio over the period 1959-88. The estimates reveal significant effects in the predicted direction for world stock returns, oll prices, and world monetary growth, but fiscal variables turned out to be unimportant. Structural estimation implies that an increase by one percentage point in the expected real interest rate raises the desired saving rate by one. third of a percentage point. Simulations of the model indicated that fluctuations in world stock returns and oil prices explain a good deal of the time series for the world average of expected real interest rates; specifically, why the rates were low in $1974-79$ and high in 1981-86. The model also explains the fall in real rates in $1987-88$ and the subsequent upturn in 1989. The fitted relation forecasts an increase in the world average of real interest rates in 1990 to a value, 5.6 , that is nearly a full percentage point above the highest value attained in the entire prior sample, 1958-89. We estimated systems of equations for individual countries' expected real interest rates and investment ratios. One finding is that each country's expected real interest rate depends primarily on world factors, rather than own-country factors, thereby suggesting a good deal of integration of world capital and goods markets.
\end{abstract}

Robert J. Barro Department of Economics Harvard University Littauer 120

Cambridge, MA 02138
Xavier Sala 1 Martin

Department of Economics

Harvard University

Cambridge, MA 02138 
We began this study with the challenge to explain why real interest rates were so high in the 1980s in the major industrialized countries. To try to address this challenge in a serious way we expanded the question to the determination of real interest rates over a longer sample, which turned out to be 1959-88. In considering how real interest rates were determined we focused on the interaction between investment demand and desired saving in an economy (ten OECD countries viewed as operating on an integrated capital market) that was large enough to justify closed-economy assumptions. Within this "world" setting, high real interest rates reflect positive shocks to investment demand (such as improvements in the expected profitability of investment) or negative shocks to desired saving (such as temporary reductions in world income). Our main analysis ends up measuring the first kind of effect mainly by stock returns and the second kind primarily by oil prices and monetary growth.

Much to our surprise, we actually think that we have partial answers to how world real interest rates have been determined, and, more specifically, to why real interest rates were as high as they were in the 1980s. The key elements in the period 1981-86 appear to be favorable stock returns (which raised real interest rates and stimulated investment) combined with high oil prices (which also raised real interest rates, but discouraged investment).

We focus in this paper on the behavior of short-term real interest rates since 1959 in nine OECD countries: Belgium (BE), Canada (CA), France (FR), Germany (GE), Japan (JA), Netherlands (NE), Sweden (SW), the United Kingdom (UK), and the United States (US). These countries constitute the set of industrialized market economies for which we have been able to obtain data since the late 1950s on relatively open-market interest rates for assets that are analogous to U.S. Treasury bills. For France and Japan, the available 
data are money-market rates. We were unable to obtain satisfactory data on interest rates for Italy (IT) prior to the early 1970s, but we included Italian data on other variables. Therefore, parts of the analysis deal with ten OECD countries. These countries accounted in 1960 for $65.4 \%$ of the overall real GDP for 114 market economies, according to the PPP-adjusted data that were constructed by Summers and Heston (1988). In 1985, the share was $63.4 \%$. Thus, the sample of ten countries represents a substantial fraction of the world's real GDP.

We have concentrated thus far on short-term interest rates because of the difficulty in measuring medium- or long-term expected inflation and hence expected real interest rates. The quantification of expected inflation is difficult even for short horizons, although we think the results in this paper are robust to these problems. The patterns that we find in short-term expected real interest rates reveal a good deal of persistence; for example, the rates are much higher for 1981-86 than for 1974-79, with the rates in the 1960 s falling in between. Given the ease with which participants in financial markets can switch among maturities, the persisting patterns in expected real short-term rates would also be reflected in medium- and long-term rates. Therefore, we doubt that the limitation of the present analysis to short-term rates will turn out to be a serious drawback. We plan, however, to apply the approach also to longer term rates.

\section{Expected Inflation and Expected Real Interest Rates}

Investment demand and desired saving depend on expected real interest rates. The data provide measures of nominal interest rates and realized real rates. We could carry out the analysis with the realized real rates, relying 
on a rational-expectations condition to argue that the difference between the realized and expected real rates, which corresponds to the negative of the difference between the actual and expected inflation rate, involves a serially uncorrelated random error. Because the divergences between actual and expected inflation are likely to be large in some periods, we would obtain much more precise estimates if we could construct reasonably accurate measures of expected inflation and expected real interest rates. Thus, we begin by estimating expected inflation rates.

We have quarterly, seasonally unadjusted data on an index of consumer prices for each country beginning in 1952.1. (For the United States, we used the CPI less shelter to avoid problems with the treatment of housing costs in the data prior to 1983.) The results reported in this paper compute expected inflation for dates $\mathrm{t}=1958.1$ to $\mathbf{1 9 8 9 . 4}$ based on regression forecasts for CPI inflation. (Quarter 1 represents the annualized inflation rate from January to April, and so on.) Each regression uses data on inflation for country $i$ from 1952.2 up to the quarter prior to date $t$. That is, the data before date $t$ are equally weighted, but later data are not used to calculate forecasts.

The functional form for the inflation regressions is an ARMA $(1,1)$ with deterministic seasonals for each quarter; thus, expected inflation is based solely on the history of inflation. We considered forms in which inflation depended also on past values of $M 1$ growth and nominal interest rates, but the effects on the computed values of expected real interest rates were minor. (The nature of the relation between inflation and past monetary growth and interest rates also varied considerably across the countries.) Within the ARMA $(1,1)$ form, the results look broadly similar across the nine OECD 
countries; typically, the estimated $\mathrm{AR}(1)$ coefficient is close to 0.9 and the estimated $M A(1)$ coefficient ranges between -0.4 and -0.8 . Q-statistics for serial correlation are typically insignificant at the $5 \%$ level, although these statistics are significant in some cases. The pattern of seasonality varies a good deal across the countries. Appendix Table A1 shows the estimated equations that apply for the nine countries over the sample 1952.2-1989.3.

We computed annual measures of expected inflation by averaging the four quarterly values from the regression forecasts. Figure 1 compares the constructed annual time series for U.S. expected inflation, $\pi_{U S, t}^{e}$, with values derived from the 6-month-ahead forecasts from the Livingston survey (obtained from the Federal Reserve Bank of Philadelphia). The two series move closely together, with a correlation of .92 from 1959 to 1988 . The main discrepancies are the more rapid adjustment of the regression-based series to actual inflation in the periods 1973-75 (when inflation rose) and 1985-86 (when inflation fell).

We calculated expected real interest rates, $r_{i t}^{e}$, for country $i$ in quarter $t$ by subtracting the constructed value for $\pi_{i t}^{e}$ from the corresponding nominal interest rate, $R_{i t}$. (The 3 -month Treasury bill rate in January matches up with the expected inflation rate for January to April, and so on.) We then formed an annual series for $r_{i t}^{e}$ by averaging the four quarterly values.

The calculated values for U.S. expected real interest rates for 1974-77 are negative and average $-1.2 \%$, whereas the values based on the Livingston survey average $0.1 \%$ and are negative only for 1975-77. A plausible explanation is that the regression estimates overstate the responsiveness of expected inflation to actual inflation in the early 1970s. Many of the other 
eight OECD countries exhibit negative values of $r_{i t}^{e}$ for some of the years between 1972 and 1976, and an overstatement of $\pi_{i t}^{e}$ may also explain this behavior. (If we had used the full sample of data to compute $\pi_{i t}^{e}$, rather than just the data prior to period $t$, the calculated sensitivity of $\pi_{i t}^{e}$ to past inflation would have been even greater. Thus, the tendency to calculate negative values for $\mathrm{r}_{\mathrm{it}}^{\mathrm{e}}$ between 1972 and 1976 would have been even more pronounced.) Except for the U.K. for 1975-77 $\left(\mathrm{r}_{\mathrm{t}, \mathrm{UK}}^{\mathrm{e}}=-.115,-.027\right.$, and -.058, respectively), the computed negative values for $r_{t}^{e}$ since 1959 never exceed 27 in magnitude. 1

The subsequent analysis deals with the annual time series for expected real interest rates, $r_{i t}^{e}$. The limitation to annual values arises because some of the other variables are available only annually. ${ }^{2}$ In any event, the high serial correlation in the quarterly series on $r_{i t}^{e}$ suggests that we may not lose a lot of information by confining ourselves to the annual

${ }^{1}$ Economic theory would not rule out small negative values for expected real interest rates on nearly risk-free assets. However, opportunities for low-risk real investments without substantial transaction costs (including storage of durables) would preclude expected real rates that were substantially negative. It seems likely that at least the large-magnitude negative values for $r_{t}^{e}$ represent mismeasurement of expected inflation. It would be possible to recompute $\pi_{t}^{e}$ based on the restriction that the implied value for $r_{t}^{e}$ exceed some lower bound, such as zero or a negative number of small magnitude. We have not yet proceeded along these lines.

2 The main results that we report below turn out, however, to involve variables that are available quarterly. We are presently working on the results for quarterly data. 
observations. The use of annual data means also that we do not have to deal with possible seasonal variations in expected real interest rates.

We constructed a world index of a variable for year $t$ by weighting the value for country $i$ in year $t$ by the share of that country's real GDP for year $t$ in the aggregate real GDP of the nine- or ten-country sample. (Henceforth, the term "world" signifies the aggregate of the nine- or ten-country OECD sample.) In computing the weights, we used the PPP-adjusted numbers for real GDP reported by Summers and Heston (1988). (For 1986-89, we used the shares for 1985, the final year of their data set.) None of our results changed significantly if we weighted instead by shares in world investment. Table 1 shows the average of each country's Summers-Heston GDP weight (WT) from 1959 to 1988. Note that the average share for the United States was .45, that for Japan was .13, and so on. (In 1985, the U.S. share was .44 and the Japanese was .17.)

Figure 2 shows the world values (nine-country sample excluding Italy) for actual and expected inflation from 1959 to 1989. (Because we had data on actual inflation for some countries only up to the third quarter of 1989 , the value for actual inflation in 1989 is missing.) Expected and actual inflation move together in a broad sense, but the expected values lag behind the increases in inflation in 1969, 1972-74, and 1979-80, and behind the decreases in 1982 and 1986. Figure 3 shows the corresponding values for world actual and expected real interest rates. Although the two series move broadly together, a notable discrepancy is the excess of expected over actual real interest rates for 1972-74. The actual rates are negative over this period (averaging - 2.3\%), but the computed expected rates are positive (averaging 1.1\%). 
Figure 4 shows the breakdown of the world nominal interest rate into two components: the world expected inflation rate and the world expected real interest rate. The graph makes clear that the bulk of variations in nominal interest rates correspond to movements in expected inflation: the correlation between the nominal interest rate and the expected inflation rate is .79 , whereas that between the nominal rate and the expected real interest rate is .44. (The correlation of the nominal interest rate with actual inflation is .62 , whereas that with the actual real interest rate is .24.)

Many authors have argued that expected real interest rates among OECD countries differ significantly in terms of levels and time patterns (see, for example, Mishkin, 1984). Although our findings do not dispute this conclusion, we think nevertheless that a study of the movements of real interest rates in the main OECD countries can usefully start by attempting to explain the common elements across the countries. (Blanchard and Summers, 1984, take a similar view.) The comparison of U.S. behavior with that of the other countries in Figure 5 suggests that the common factors are worth investigating. The U.S. expected real interest rate moved similarly to the average for the other eight countries; the correlation from 1959 to 1989 was .73 .

A simple way to summarize the overall movements of the expected and actual real interest rates, $r_{w d, t}^{e}$ and $r_{w d, t}$, is to consider the means of the two variables from Figure 3 over various sub-periods. The average values for $r_{w d, t}^{e}\left(r_{w d, t}\right)$ were 2.0\% (1.8\%) for $1959-70,1.2 \%(-1.0 \%)$ for $1971-73,0.0 \%$ $(-1.0 \%)$ for $1974-79,2.4 \%(1.8 \%)$ for $1980,4.2 \%(5.3 \%)$ for $1981-86,2.3 \%$ (2.8\%) for $1987-88$, and $3.5 \%(3.4 \%)$ for 1989 . These data suggest that it is a meaningful question to ask why expected and actual real interest rates were 
high in the early 1980s. ${ }^{3}$ In our analysis of the full time series since 1959, we effectively add the questions of why the movements in rates were relatively moderate from 1959 until the early 1970s, why the rates were so low in the middle and late 1970s, and why the rates fell after 1986 and rose in 1989 .

\section{A Model of Investment Demand and Desired Saving}

We think of "the" world expected real interest rate, $r_{w d, t}^{e}$, as determined by the equation in period $t$ of world investment demand to world desired saving. This setting applies to the ten-country OECD sample if first, these countries operated throughout the sample on integrated capital and goods markets, and second, if the ten countries approximate the world, and hence a closed economy. We get some insight later about the integration of world markets by analyzing the extent to which real interest rates in individual countries respond to own-country variables rather than to world variables. The approximation that the ten countries represent the world and hence a closed economy may be tenable first, because these countries constitute about $65 \%$ of the world's real GDP (for market economies), and second, because the observed current-account balance for the ten-country aggregate has been very small. We added up each country's nominal current-account balance (expressed via current exchange rates in terms of U.S. dollars) from 1960 to 1987 and divided by the total nominal GDP (also converted by exchange rates into U.S.

\footnotetext{
${ }^{3}$ The rates for 1981-86 would not look so high in an historical context that went before World Var II. Barro $(1989$, p. 242) shows that U.S. realized real interest rates on assets comparable to prime commercial paper averaged about 8\% from 1840 to 1900 (excluding the Civil War), $3 \%$ from 1900 to 1916 , and $5 \%$ from 1920 to 1940 .
} 
dollars). The average value of the ratio of the aggregated current-account balance to overall GDP was 0.1\%. Moreover, the largest value from 1960 to 1987 (1971) was only $0.5 \%$ and the smallest (1984) was only $-0.7 \%$.

We now construct a simple model of investment demand and desired saving. Although we use the model to interpret some of the empirical findings, the general nature of the reduced-form results does not depend on this particular framework. Hence, readers who are unimpressed by our theory may nevertheless be interested in the empirical evidence.

We measure real investment, $I_{t}$, by gross domestic capital formation (private plus public, non-residential plus residential, fixed plus changes in stocks). Thus $I_{t}$ excludes purchases of consumer durables and expenditures on human capital. Investment demand, expressed as a ratio to GDP, is determined by a $q$-type variable:

$$
(\mathrm{I} / \mathrm{Y})_{\mathrm{t}}=a_{0}+a_{1} \cdot \log \left[\mathrm{PROF}_{\mathrm{t}}^{\mathrm{e}} /\left(\mathrm{r}_{\mathrm{t}}^{\mathrm{e}}+\rho_{\mathrm{t}}\right)\right]+\mathrm{u}_{\mathrm{t}}
$$

where $\mathrm{PROF}_{t}^{\mathrm{e}}$ is expected profitability per unit of capital, $\mathrm{r}_{t}^{\mathrm{e}}$ is the expected real interest rate on assets like Treasury bills, $\rho_{t}$ is a risk premium, and $a_{1}>0$. The error term $u_{t}$ is likely to be highly persistent because first, time-to-build considerations imply that current investment demand depends on lagged variables that influenced past investment decisions, and second, there may be permanent shifts in the nature of adjustment costs, which determine the relation between investment demand and the $q$ variable. In firstdifference form, equation (1) becomes 


$$
(\mathrm{I} / \mathrm{Y})_{\mathrm{t}}=\alpha_{1} \cdot \Delta \log \left[\operatorname{PROF}_{\mathrm{t}}^{\mathrm{e}} /\left(\mathrm{r}_{\mathrm{t}}^{\mathrm{e}}+\rho_{\mathrm{t}}\right)\right]+(\mathrm{I} / \mathrm{Y})_{\mathrm{t}-1}+\mathrm{u}_{\mathrm{t}}-\mathrm{u}_{\mathrm{t}-1}
$$

Our analysis treats the error term, $u_{t}-u_{t-1}$, as roughly white noise.

We use the world real rate of return on the stock market through December of the previous year, STOCK $_{t-1}$, to proxy for the first difference of the $q$ variable, $\Delta \log \left[\mathrm{PROF}_{\mathrm{t}}^{\mathrm{e}} /\left(\mathrm{r}_{\mathrm{t}}^{\mathrm{e}} \rho_{\mathrm{t}}\right)\right] .4$ This proxying is imperfect because of distinctions between average and marginal $q, 5$ because of failure to adjust for changes in the market value of bonds and depreciation of capital stocks, and because the stock market values only a portion of the capital that relates to our measure of investment. (The investment numbers include residential construction, non-corporate business investment, and public investment.) For these reasons, the best estimate of $\Delta \log \left[\operatorname{PROF}_{t}^{e} /\left(r_{t}^{e}+\rho_{t}\right)\right]$ would depend inversely on the change in $r_{t}^{e}$, for a given value of STOCK $t-1 .{ }^{6}$

4The stock-return variable for each country is the nominal rate of return for the year implied by the IFS December index for industrial-share prices less the December-to-December inflation rate based on the consumer price index. We had broader stock-return measures readily available for three countries-Canada, the U.K., and the U.S. -which together comprised $57 \%$ on average of the ten-country GDP. The substitution of these numbers for the IFS values had a negligible impact on the regression results that we report later. We took this result as an indication that the IFS data are probably satisfactory indicators of stock-market returns.

${ }^{5}$ See Hayashi (1982). He discusses, in particular, the adjustments of marginal q for tax effects.

${ }^{6}$ Let $\operatorname{STOCK}_{t}=\operatorname{\Delta log}\left(q_{t}\right)+e_{t}$, where $q_{t}=\left[\operatorname{PROF}{ }_{t}^{e} /\left(r_{t}^{e}+p_{t}\right)\right]$ and $e_{t}$ can be interpreted as a measurement error. Assume that the prior distribution is given by $\Delta \log \left(q_{t}\right)=\epsilon_{t}$, that $r_{t}^{e}$ is observed without error, and that no direct information about $\rho_{t}$ is available. Then the posterior estimate of $\Delta \log \left(q_{t}\right)$ gives weights to $\operatorname{STOCK}_{t}$ and (as a linear approximation) to $r_{t}^{e}-r_{t-1}^{e}$, where the weight on $r_{t}^{e}-r_{t-1}^{e}$ rises with $\operatorname{VAR}(e) / \operatorname{VAR}(\epsilon)$. (Independent measurement error in $r_{t}^{e}$ would lower the weight applied to $r_{t}^{e}-r_{t-1}^{e}$ ) Our analysis uses data on 
Therefore, we approximate the relation for investment demand as

$$
(I / Y)_{t}=a_{0}+a_{1} \cdot S T 0 C K_{t-1}-a_{2} \cdot\left(r_{t}^{e}-r_{t-1}^{e}\right)+(I / Y)_{t-1}+v_{t}
$$

where $a_{1}>0$ and $a_{2}>0.7$

We assume that the desired saving rate (for the world aggregate of national saving) is given by

$$
(\mathrm{S} / \mathrm{Y})_{\mathrm{t}}=\beta_{0}+\beta_{1}(\tilde{\mathrm{Y}} / \mathrm{Y})_{\mathrm{t}}+\beta_{2} \mathrm{r}_{\mathrm{t}}^{\mathrm{e}}+\beta_{3} \cdot(\mathrm{S} / \mathrm{Y})_{\mathrm{t}-1}+\text { error term }
$$

where $\tilde{Y}_{t}$ is current temporary income, the $\beta_{i}$ 's are positive, and the error term is treated as white noise. Equation (4) adopts the permanent-income perspective in assuming that permanent changes in income do not have important effects on the saving rate. Temporary changes in income have little effect on consumer demand and therefore have a positive effect on the desired saving rate, as given by the coefficient $\beta_{1}$. Given the temporary-income ratio, $(\tilde{Y} / Y)_{t}$, the saving rate would respond positively to $r_{t}^{e}$ in accordance with the coefficient $\beta_{2}$. The variable $(S / Y)_{t-1}$ picks up

stock returns only through December of the previous year (and thereby avoids some simultaneity problems). The omission of contemporaneous data on stock returns raises $\operatorname{VAR}(e)$ and thereby raises the weight applied to $r_{t}^{e}-r_{t-1}^{e}$.

${ }^{7}$ The term $\left(r_{t}^{e}-r_{t-1}^{e}\right)$ is approximately linear if $\rho_{t} \gg r_{t}^{e}$ applies. 
persisting influences on the saving rate. It turns out in our empirical estimation that $0<\beta_{3}<1$ applies; that is, the desired saving rate appears to exhibit less persistence than the investment-demand ratio, which has a unitary coefficient on the lagged dependent variable in equation (3).

We considered using measures of temporary government purchases, especially defense expenditures, as influences on temporary income and hence desired national saving rates. Up to this point, however, we have been unable to isolate important temporary variations in the ratios of real government purchases to real GDP over the period since 1959 for the ten OECD countries that we are studying.

We have had more success by thinking of the relative price of oil as an indicator of world temporary income. Higher oil prices are bad for oil importers, which predominate in the ten-country OECD sample. Because higher oil prices tend to reflect more effective cartelization of the market for oil, an increase in prices also represents a global distortion that is bad for the world as a whole. Moreover, high oil prices may be a signal of disruption of international markets in a sense that goes beyond oil; therefore the effects on world income may be substantially greater than those that could be attributed to oil, per se.

Our subsequent analysis of real interest rates provides some indication that the level of the relative price of oil, rather than the change in this relative price, is the variable that proxies for temporary income. This result is reasonable if people perceive the relative price of oil to be stationary; in this case, a high level for the current relative price signals a temporarily high level. In the actual time series (Figure 7 ), the relative price of oil did happen to return after 1985 to values close to those 
applying before 1973. But our direct analysis of the time-series properties of the relative oil price is inconclusive about stationarity. 8

The empirical analysis uses the variable POIL $\mathrm{t}_{\mathrm{t}-1}$, which is the relative price of crude petroleum for December of the previous year from the U.S. producer price index. The results do not change significantly if we use instead a weighted average of relative petroleum prices for each country. The precise concepts for these prices varied across the countries and the data for some countries were unavailable for parts of the sample. For these reasons, we used the U.S. variable in the main analysis.9

Thinking of $\mathrm{POIL}_{\mathrm{t}-1}$ as an inverse measure of the temporary income ratio, $(\tilde{Y} / Y)_{t}$, the equation for the saving rate becomes

$$
(S / Y)_{t}=b_{0}-b_{1} \cdot P 0 I L_{t-1}+b_{2} \cdot r_{t}^{e}+b_{3} \cdot(S / Y)_{t-1}+\text { error term }
$$

where the $b_{i}$ 's are positive. He assume that, given the stock return, STOCK $_{\mathrm{t}-1}$, the variable POIL $_{\mathrm{t}-1}$ does not shift investment demand in equation (2). That is, at least the main effects of oil prices on investment demand are assumed to be captured by the stock-market variable. With this

${ }^{8}$ Even if the relative price of oil is non-stationary, the consequences of a change in the price of oil for world income are likely to be partly. transitory. In particular, the effects on income would tend to diminish as methods of production adjusted to the new configuration of relative prices.

${ }^{9}$ The results are also similar if we use the dollar price for Venezuelan crude instead of the U.S. PPI for crude petroleum. (The Saudi Arabian price is very close to the Venezuelan price, but the IFS does not report the Saudi Arabian values after 1984.) The main difference between the Venezuelan and U.S. series is that the Venezuelan one shows a much larger proportionate increase in 1973. 
interpretation, the variable $\mathrm{POIL}_{t-1}$ represents a shift to desired saving that is not simultaneously a shift to investment demand.

We also assume that the stock-market return, STOCK $_{t-1}$, has primarily permanent effects on income; that is, we neglect effects on the temporary income ratio, $(\tilde{Y} / Y)_{t}$, and thereby on desired saving in equation (4). Given this assumption, the variable STOCK $_{t-1}$ reflects a shift to investment demand that is not simultaneously a shift to desired saving. In other words, the variables STOCK $\mathrm{t}-1_{1}$ and $\mathrm{POIL}_{\mathrm{t}-1}$ will allow us to identify the relations for investment demand and desired saving.

We might be able to quantify the interplay between stock returns and temporary income by using measures of current profitability, such as after-tax corporate profits. That is, we could estimate the implications of stock returns for the part of temporary income that relates to the difference between current and expected future profitability. We have thus far been unsuccessful in obtaining satisfactory measures of corporate profits for some of the countries in the sample, and therefore have not yet implemented this idea. (The main data series available from the OECD, called "operating surplus," is an aggregate that is much broader than corporate profits.) The limited data that we have indicate that current stock returns or other variables lack significant predictive content for future changes in the ratio of corporate profits to GDP. Therefore, it may be roughly correct that stock returns have little interplay with the temporary income that corresponds to gaps between current and expected future corporate profits.

We now extend the analysis to consider the effects of monetary and fiscal variables. He think of these variables as possible influences on the desired saving rate in equation (4). In some models where money is non-neutral-such 
as Keynesian models with sticky prices or wages-a higher rate of monetary expansion raises temporary income and thereby increases the desired saving rate. ${ }^{10}$ With respect to fiscal variables, many economists (such as Blanchard, 1985) argue that increases in public debt or in prospective budget deficits reduce desired national saving rates.

Let $\mathrm{DM}_{\mathrm{t}-1}$ be a measure of monetary expansion and $\mathrm{F}_{\mathrm{t}-1}$ be a measure of fiscal expansion, each applying up to the end of year $t-1$. Then we can expand the relation for the desired saving rate from equation (5) to

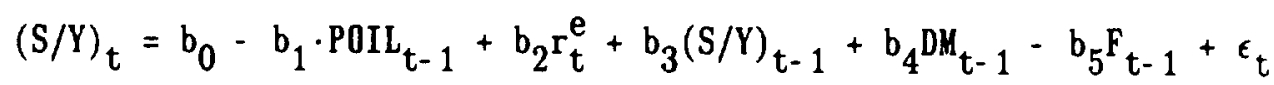

The coefficients are defined so that $b_{i}>0$ applies in the theoretical arguments discussed above.

Given our closed-economy assumption (for the ten-country OECD sample), $r_{t}^{e}$ is determined by equating the investment-demand ratio, $(I / Y)_{t}$ from equation $(3)$, to the desired saving rate, $(S / Y)_{t}$ from equation (6). The reduced-form relations for $r_{t}^{e}$ and $(I / Y)_{t}$ are as follows:

$$
\begin{aligned}
r_{t}^{e}=\frac{1}{\left(a_{2}+b_{2}\right)} \cdot\left[a_{0}-b_{0}+a_{1} \cdot \operatorname{STOCK}_{t-1}+b_{1} \cdot P_{0 I L} L_{t-1}+a_{2} \cdot r_{t-1}^{e}\right. \\
\left.+\left(1-b_{3}\right) \cdot(I / Y)_{t-1}-b_{4} \cdot D M_{t-1}+b_{5} \cdot F_{t-1}+v_{t}-\epsilon_{t}\right]
\end{aligned}
$$

\footnotetext{
10 In the analysis of Mundell (1971), higher monetary expansion leads to higher expected inflation and thereby to a lower real demand for money. The reduction in real money balances is assumed to lead to a decrease in consumer demand and hence to an increase in the desired saving rate. Tobin (1965) gets an increase in the desired saving rate in a similar manner.
} 
(8)

$$
\begin{aligned}
(I / Y)_{t}= & \frac{1}{\left(a_{2}+b_{2}\right)} \cdot\left[a_{0} b_{2}+a_{2} b_{0}+a_{1} b_{2} \cdot \operatorname{STOCK}_{t-1}-a_{2} b_{1} \cdot P O I L_{t-1}+a_{2} b_{2} \cdot r_{t-1}^{e}\right. \\
& \left.+\left(b_{2}+a_{2} b_{3}\right) \cdot(I / Y)_{t-1}+a_{2} b_{4} \cdot D M_{t-1}-a_{2} b_{5} \cdot F_{t-1}+a_{2} \epsilon_{t}+b_{2} v_{t}\right]
\end{aligned}
$$

The reduced form of the model in equations (7) and (8) implies

1. Higher stock returns, $\operatorname{STOCK}_{t-1}$, raise $r_{t}^{e}$ and $(I / Y)_{t}$,

2. Higher oil prices, $\mathrm{POIL}_{\mathrm{t}-1}$, raise $\mathrm{r}_{\mathrm{t}}^{\mathrm{e}}$ but lower $(\mathrm{I} / \mathrm{Y})_{\mathrm{t}}$,

3. Higher monetary growth, $D M_{t-1}$, lowers $r_{t}^{e}$ and raises $(I / Y)_{t}$ (in models where monetary expansion stimulates desired saving),

4. Greater fiscal expansion, $F_{t-1}$, raises $r_{t}^{e}$ and lowers $(I / Y)_{t}$ (in models where fiscal expansion reduces desired national saving).

Two additional implications that concern lagged dependent variables are more dependent on the dynamic effects built into the model structure:

5. The lagged value $r_{t-1}^{e}$ has positive effects on $r_{t}^{e}$ and $(I / Y)_{t}$ (because, holding fixed the other variables including $(I / Y)_{t-1}$, a higher $\mathrm{r}_{\mathrm{t}-1}^{\mathrm{e}}$ effectively shifts up investment demand),

6. The lagged value $(I / Y)_{t-1}$ has a positive effect on $(I / Y)_{t}$ because of the persistence built into investment demand and desired saving. The effect on $r_{t}^{e}$ is positive if the persistence in investment demand is greater than that in desired saving; that is, if $b_{3}<1$.

Empirical Analysis of Expected Real Interest Rates and Investment Ratios

Table 1 contains means and standard deviations for the main variables used in the analysis. Table $A 2$ in the appendix has definitions and sources for the variables. The world ratio of real investment (gross domestic capital formation) to real GDP appears in Figure 6 . We use figures on gross 
investment because the data on depreciation are likely to be unreliable. As with the other world measures, the investment ratio is the GDP-weighted value of the numbers from the ten OECD countries. World real stock returns (December-to-December) are in Figure 7, the December values for the relative price of oil are in Figure 8, and world growth rates of M1 (December-toDecember) are in Figure 9.

Figures 10-13 show various measures of fiscal stance. Figure 10 plots the ratios of real central government debt to real GDP for the United States and the nine other OECD countries.11 (We presently lack data for 1988 on the debt of some of the countries.) Note that the pattern for the United States is broadly similar to that for the average of the other countries. Note also that the U.S. debt-GDP ratio peaked in 1987 and fell in 1988.

We define the real budget deficit to be the change during the year in the central government's outstanding real debt. Figure 11 shows world values for this concept of the real budget deficit when expressed as a ratio to real GDP. We plot the actual and cyclically-adjusted values of the ratio. The cyclically-adjusted values are the residuals from a regression for each country over 1958-87 of the real deficit-real GDP ratio on the current and four annual lags of the growth rate of real GDP.

Figures 12 and 13 compare the U.S. ratios for real budget deficits to real GDP with those for the nine other countries. Figure 12, which plots

1 We lack data on debt for consolidated general government on a consistent basis for the ten countries in the sample. The figures that we used, which were computed in most cases from IFS numbers on the par value of the aggregate of domestic and foreign debt for central governments, are gross of holdings by central banks, certain government agencles, and local governments. 
ratios for actual real budget deficits, shows that the recent U.S. experience did not depart greatly from that for the average of the other nine countries. Figure 13 shows, however, that recent values for the cyclically-adjusted U.S. ratios were substantially higher than those for the average of the other nine countries. On the other hand, the adjusted U.S. ratio fell from 4.0\% in 1986 to $1.9 \%$ in 1987 and $1.0 \%$ in 1988 .

Reduced-Form Estimates for the World Expected Real Interest Rate

We begin the empirical analysis with reduced-form equations for the world (nine-country) expected real interest rate, $r_{w d, t}^{e}$, over the period 1959 to 1988. Table 2, col. 1, shows a regression of the form of equation (7), but with monetary and fiscal variables excluded. The estimated coefficients of STOCK $_{w d, t-1}(.041$, s.e. $=.011)$ and $\mathrm{POIL}_{\mathrm{t}-1}(.029$, s.e. $=.009)$ are each positive and significant, with t-values of 3.7 and 3.1 , respectively. Not surprisingly, the estimated coefficient of $r_{w d, t-1}^{e}$ is also positive and highly significant $(.58$, s.e. $=.10)$. The estimated coefficient of $(\mathrm{I} / \mathrm{Y})_{\mathrm{wd}, \mathrm{t}-1}$ is positive $(.22$, s.e. $=.15)$, but not statistically significant at the $5 \%$ level.

Table 2, col. 2 adds the monetary variable, $D M_{w d, t-1}$, which is the GDP-weighted average of world M1 growth through December of the previous year.12 We were surprised to find that $D M_{w d, t-1}$ entered negatively and

12 We also examined the growth rates of currency and nominal GNP as alternative measures of monetary stimulus. If the growth rate of currency through the end of year $t-1$ is added to the basic regression from Table 2, col. 2 (which includes M1 growth for year t-1), the estimated coefficient of the new variable is insignificant and the other results change little. If the growth rate of world nominal GDP for year $t-1$ is added to the basic regression, the estimated coefficient of the new variable is -.167 , s.e. = $.093, \mathrm{t}$-value $=1.8$. The other results change little; in particular, the 
significantly in the regression for $\mathrm{r}_{\mathrm{wd}, \mathrm{t}}^{\mathrm{e}}(-.251$, s.e. $=.054, \mathrm{t}$-value $=$ 4.7). (We were surprised because previous research suggested difficulty in isolating these kinds of monetary effects; see, for example, Barro [1981].) Moreover, when $D M_{w d, t-1}$ is added to the regression, the estimated coefficients for the other variables become more significant: the t-values are now 6.7 for STOCK $_{w d, t-1}(.064 \text {, s.e. }=.009)^{13}$ and 5.5 for POIL t- $1(.039$, s.e. $=.007) .14$ The estimated coefficient of $(I / Y)_{w d, t-1}$ also becomes significantly positive $(.49$, s.e. $=.12)$, with a t-value of 3.9 .

It is possible that the apparent effect of $\mathrm{M} 1$ growth represents some kind of endogenous response of money to the economy, rather than the influence of exogenous monetary growth on real interest rates. Our failure in the next section to find the predicted positive relation between $D M_{w d, t-1}$ and the investment ratio, $(I / Y)_{t}$, may support alternative interpretations based on endogenous money. He carried out some analys is of monetary reaction

estimated coefficient of $\mathrm{DM}_{\mathrm{wd}, \mathrm{t}-1}$ is -.250 , s.e. $=.051$, which is virtually unchanged from that shown in Table 2, col. 2. (The world growth rates of M1 and nominal GDP are essentially orthogonal.) The nearly signif icant negative coefficient on the lag of nominal GDP growth may indicate that exogenous shifts in velocity have negative effects on expected real interest rates. ${ }^{13}$ The estimated coefficient of STOCK $_{w d, t-1}$ changes little if the individual stock returns are weighted by each country's share of world investment, rather than GDP. With investment weights, the estimated coefficient of STOCK $_{\text {wd } t-1}$ is .060 , s.e. $=.010$.

14 If we add the second lag value, $\mathrm{POIL}_{t-2}$, the estimated coefficient is -.023 , s.e. $=.020$. The hypothesis that only the change in the relative price of oil, $\mathrm{POIL}_{\mathrm{t}-1}-\mathrm{POIL}_{\mathrm{t}-2}$, matters is rejected at the $5 \%$ level (t-value = 2.7). If we replace the U.S. relative price of oil by a GDP-weighted average of individual country relative prices, the estimated coefficient of POIL becomes .042 , s.e. $=.010$ (and the $R^{2}$ of the regression falls from .892 to $.875)$. 
functions; these results indicate a negative response of monetary growth to oil prices and stock returns, but not to lags of expected real interest rates or investment ratios. $\left(\mathrm{DM}_{\mathrm{wd}, t}\right.$ is itself serially uncorrelated; see Figure 9.) Because we already held fixed the stock market and oil prices in the regression for $r_{w d, t}^{e}$, we do not see how our findings about monetary reaction can explain the relation between $D M_{w d, t-1}$ and $r_{w d, t}^{e}$ based on a story about endogenous money. Monetary growth would have to be reflecting information about future real interest rates that is not already contained in the other explanatory variables.

The explanatory power of $D M_{w d, t-1}$ for $r_{w d, t}^{e}$ reflects in part the wellknown cutback in world M1 growth in 1979 and 1980 (6.8\% and 5.3\%, respectively, compared with a mean of $8.0 \%$ for 1959-88). This monetary contraction matches up well with the increase in $r_{w d, t}^{e}$ from $0.9 \%$ in 1979 to $2.4 \%$ in 1980 and $4.7 \%$ in 1981 . (With the monetary variable excluded in Table 2, col. 1, the fitted values of $r_{w d, t}^{e}$ for 1980 and 1981 are 2.0\% and 3.4\%, respectively. With the monetary variable included in col. 2 , these fitted values become $2.5 \%$ and $4.4 \%$.) On the other hand, the significance of $D M_{w d, t-1}$ in the regression for $r_{w d, t}^{e}$ does not depend on the inclusion of the observations for 1980-81. If these two years are omitted, the estimated coefficient of $\mathrm{DM}_{\mathrm{wd}, \mathrm{t}-1}$ becomes - .233 , s.e. $=.066$, and the other results do not change much from those shown in column 2 .

We have carried out the estimation using the realized real interest rate, $r_{w d, t}$, rather than our constructed measure of the expected rate, $r_{w d, t}^{e}$. The error term in the regression can then be viewed as including the discrepancy between the actual and expected real rate. Under rational expectations, this expectational error would be independent of the explanatory variables, which 
are all lagged values. The estimates would therefore be consistent, but inefficient relative to a situation where $r_{w d, t}^{e}$ is observed directly and used as the dependent variable. Although the standard errors of the estimated coefficients are substantially higher where $r_{w d, t}$ replaces $r_{w d, t}^{e}$ as the dependent variable, the basic pattern of the results remains the same. Thus, the findings do not depend on our particular measure for expected inflation.

0verall, the regression equation in Table 2, col. 2 does a remarkable job of explaining the variations in expected real interest rates from 1959 to 1988; see Figure 14 for a plot of actual values against fitted values and residuals. Note that the out-of-sample forecast of $r_{w d, t}^{e}$ for 1989 is $3.2 \%$ compared to an actual of $3.5 \%$; for 1988 , the estimated value was $1.9 \%$ and the actual was 2.3\%. (We promise that we generated the forecast for 1989 before finding the data on the actual value.)

We will discuss more features of the results later, but some key elements for the 1980s are the generally favorable stock-market returns combined with high oil prices. (Blanchard and Summers, 1984, argued that improved prospects for profitability-which we pick up in the stock-market returnswere an important element in the high real interest rates of the 1980s.) The experience for the 1980 s contrasts with the extremely poor stock returns and lower oil prices that prevailed in the mid 1970s. On the other hand, the 1960s featured still lower oil prices, but better stock returns than in the mid 1970s.

Columns 3 and 4 add fiscal variables to the regression for $r_{w d, t}^{e}$. Column 3 shows a positive but insignificant coefficient on the world debt-GDP ratio, RDEBTY $_{w d, t-1}$, and a negative but insignificant coefficient on the world ratio 
of real budget deficits to real GDP, RDEFY $w d, t-1 .{ }^{15}$ The F-statistic for the inclusion of the two fiscal variables jointly is $\mathrm{F}_{22}^{2}=1.6$ (5\% critical value $=3.4)$. Column 4 replaces RDEFY $_{w d, t-1}$ with the cyclically-adjusted variable, RDEFYA $w d, t$. The adjustment of real deficits for cyclical factors would be desirable in the present context if the removal of these factors raises the forecasting power for future ratios of real deficits to real GDP. The estimated coefficient on RDEFYA ${ }_{w d, t-1}$ is close to zero, and that on RDEBTY $_{w d, t-1}$ remains positive but insignificant. The F-statistic for the inclusion of the two fiscal variables is now only $\mathrm{F}_{22}^{2}=0.3$.

The real budget deficit is effectively an adjustment of the nominal deficit for the effect of actual inflation on the outstanding nominal debt. An adjustment for expected rather than actual inflation is likely to be preferable from the standpoint of forecasting future real budget deficits (because unexpected inflation is unpredictable). We calculated ratios of real budget deficits to real GDP (adjusted or unadjusted for cyclical fluctuations) in this manner, but the results differed negligibly from those found with actual inflation.

We also held fixed the ratio of government consumption purchases to GDP (which entered insignificantly) and experimented with the inclusion of current or future real budget deficits. In all cases we obtained similar results; the measures of fiscal stance that we have considered do not help significantly in explaining the time series for expected real interest rates. We are forced to conclude that the evidence supports the Ricardian view,

\footnotetext{
15 Negative estimated effects of budget-deficit variables on interest rates were reported previously by Evans (1987) (for nominal rates in six OECD countries) and Plosser (1987)(for nominal and real rates in the United States).
} 
which deemphasizes the roles of public debt and budget deficits in the determination of real interest rates.

Column 5 in Table 2 uses the world nominal interest rate, $R_{w d, t}$, as the dependent variable and adds the constructed measure of world expected inflation, $\pi_{w d, t}^{e}$, on the right side. Measurement error in $\pi_{w d, t}^{e}$ would bias the estimated coefficient toward zero, but the estimated value $(.89$, s.e. = .09) differs insignificantly from one. Of course, to the extent that countries levy taxes on nominal interest payments, the predicted coefficient would be somewhat above unity.

We tested for the stability of the relation between $r_{w d, t}^{e}$ and the explanatory variables by estimating the specification from Table 2, col. 2 separately for 1959-72 and 1973-88. Thus, we split the sample before the oil crises and the main changes in the international monetary system. The estimates for the two sub-periods appear in columns 6 and 7 of the table. The test for stability leads to the statistic $F_{18}^{6}=0.2$; thus, we do not reject the hypothesis that the same equation applies over both periods. To some extent, the failure to reject reflects the high standard errors that apply to the estimated coefficients for $1959-72$ (col. 6). For example, the standard error for the estimated coefficient of $\mathrm{POIL}_{\mathrm{t}-1}$ is enormous because of the small variations in relative oil prices from 1958 to 1971 (see Figure 7).16 On the other hand, the data for $1959-72$ do generate marginally

16 The estimated coefficient of $\mathrm{POIL}_{\mathrm{t}-1}$ differs insignificantly from zero for samples that begin in 1959 and end as recently as 1979; for the 1959-79 sample, the estimated coefficient is -.003 , s.e. $=.034$. If the sample ends in 1980 , the estimated coefficient becomes .029 , s.e. $=.018$. For samples that end between 1981 and 1988 , the estimated coefficient is very stable, varying between .038 and .040 with a standard error between .007 and .010 . 
significant estimated coefficients on STOCK $_{w d, t-1}(.047$, s.e. $=.028)$ and $\mathrm{DM}_{\mathrm{wd}, \mathrm{t}-1}(-.240$, s.e. $=.132)$.

Reduced-Form Estimates for Vorld Investment Ratio

We now consider the reduced form for the investment ratio in equation (8). Table 3 shows regressions over 1959-88 for the world ratio of real investment to real GDP, $(I / Y)_{w d, t}$. The explanatory variables in these equations are the same as those used in Table 2 . In the regression shown in Table 3 , column 2 , the main results are a significantly positive effect from STOCK $_{w d, t-1}(.034$, s.e. $=.011), 17$ a significantly negative effect from POIL $_{\mathrm{t}-1}(-.017$, s.e. $=.008)$, and a significantly positive effect from the lagged dependent variable $(I / Y)_{w d, t-1}(.79$, s.e. $=.14)$. The estimated coefficients of $r_{w d, t-1}^{e}(.00$, s.e. $=.08)$ and $D M_{w d, t-1}(.022$, s.e. $=.060)$ are insignificant. Figure 14 plots the actual values for $(I / Y)_{w d, t}$ along with the estimated values and residuals.

The results on the world investment ratio are consistent with the hypothesis that more favorable stock returns raise investment (along with raising real interest rates) and that higher oil prices reduce investment (along with increasing real interest rates). On the other hand, although we found before that the expected real interest rate was negatively related to last year's monetary growth, the results do not reveal the expected positive response of the investment ratio.

17 Previous results of a similar nature for the United States were reported by Fama (1981). Barro (1990) reports analogous findings for the United States and Canada. 
Columns 3 and 4 of Table 3 add the fiscal variables that we considered before; col. 3 uses the world variable for ratios of real budget deficits to real GDP, and col. 4 the variable for cyclically-adjusted ratios. The estimated effect of the debt-GDP ratio, RDEBTY $w d, t-1$, is negative but insignificant in both cases. The estimated effects of the budget-deficit variables, RDEFY ${ }_{w d, t-1}$ and RDEFYA $w d, t$, are each significantly positive; that is, the sign opposite to that predicted by models where fiscal expansion lowers the desired national saving rate. The positive effect for the unadjusted variable, RDEFY ${ }_{w d, t-1}$, accords with the negative coefficient for this variable in the interest-rate equation (Table 2, col. 3). However, the cyclically-adjusted variable, RDEFYA ${ }_{w d, t-1}$, had a coefficient of about zero in the interest-rate equation (Table 2, col. 4). The fiscal variables considered are jointly insignificant for the investment ratio at the $5 \%$ level. In the regression shown in Table 3 , col. 3 , the statistic is $\mathrm{F}_{22}^{2}=3.2(5 \%$ critical value $=3.4)$. For that in col. 4 , the statistic is $\mathrm{F}_{22}^{2}=2.6$. Thus, as with the expected real interest rate, the fiscal variables do not have much explanatory power for the investment ratio.

We $f$ it the equation for the investment ratio (Table 3, col. 2) separately over 1959-72 and 1973-88. A test of stability for the coefficients yields the statistic $F_{18}^{6}=1.7(5 \%$ critical value $=2.7)$. Columns 5 and 6 show the estimates obtained over the two sub-periods. The standard errors for the estimated coefficients from the 1959-72 sample tend to be high; however, the estimated coefficient of $\operatorname{STOCK}_{w d, t-1}$ is positive $(.018$, s.e. $=.011)$.

System Estimates for Horld Expected Real Interest Rate and Investment Ratio The structural model in equations (3) and (6) led to the reduced-form 
equations (7) and (8) for the expected real interest rate and investment ratio. In the previous sections, we estimated the two reduced-form equations separately, ignoring the overidentifying restrictions that came from the structure. In this section we estimate the two equations as a joint system, allowing for the imposition of the model's restrictions as well as for correlation of the error terms across the equations. Table 4 shows the resulting estimates for the structural coefficients that appear in equation (3) for investment demand and in equation (6) for desired saving. Columns 1 and 2 apply to a system that includes monetary growth but excludes fiscal variables. Columns 3 and 4 add two fiscal variables: the debt-GDP ratio, RDEBTY $_{w d, t-1}$, and the cyclically-adjusted real deficit-real GDP ratio, RDEFYA $_{w d, t-1}$.

We also fit the joint systems for the expected real interest rate and the investment ratio without the restrictions imposed by the structural model. Thereby we were able to compute likelihood-ratio tests of the overidentifying restrictions. For the model without fiscal variables, the test statistic (for $-2 \cdot \log [$ likelihood ratio]) of 9.9 compared to a $5 \%$ critical value from the $\chi^{2}$ distribution with 5 degrees of freedom of 11.1 . In the model with fiscal variables, the test statistic of 13.7 compared to the $5 \%$ critical value (with 7 d.f.) of 14.1. Thus, the model's restrictions were not rejected at the $5 \%$ level in either case. Table 4 also compares the fits (in terms of $R^{2}$ and $\hat{\sigma}$ values) for restricted and unrestricted forms of each equation separately. The fits for the investment equation appear substantially more sensitive than those for the interest-rate equation to the imposition of the model's overidentifying restrictions. 
The two fiscal variables are jointly insignificant when added to the restricted joint system (likelihood-ratio statistic of 5.3 compared to a $5 \%$ critical value of 6.0 ). Since the other results are not sensitive to the exclusion of the fiscal variables, we focus now on the estimates from the model that excludes the fiscal variables (columns 1 and 2 of Table 4).

If one takes the structural model seriously, then two interesting results are the estimated responsiveness of the desired saving rate to the expected real interest rate $(.34$, s.e. $=.07$ from Table 4, col. 2$)$ and the estimated reaction of the investment-demand ratio to the expected real interest rate $(-.44$, s.e. $=.13$, from col. 1). The last coefficient has to be interpreted as the effect of $r_{w d, t}^{e}$ on the investment-demand ratio while holding fixed the value of the stock market. (Recall that, when the stock return is an imperfect measure of $\Delta q_{t}$, the variable $r_{t}^{e}-r_{t-1}^{e}$ provides some independent information about $\Delta q_{t} \cdot$ ) The dependence of the stock return on $r_{w d, t}^{e} r_{w d, t-1}^{e}$ suggests that the estimated coefficient -.44 would underestimate the magnitude of the response of the investment-demand ratio to $r_{w d, t}^{e}$ while holding fixed expected profitability, PROF ${ }_{t}^{e}$, and the risk premium, $\rho_{t}$, but not the value of the stock market.18

The estimated model implies that desired national (gross) saving rates rise by .34 percentage points for each percentage-point increase in $r_{t}^{e}$. Although this form provides a natural unit for thinking of the responsiveness

\footnotetext{
$180 \mathrm{n}$ the other hand, serial correlation of the error term in the equation for $r_{\mathrm{wd}, t}^{e}$ would likely lead to an overestimate of the sensitivity of investment demand to a change in the expected real interest rate; see the coefficient $a_{2}$ in equations (3) and (7).
} 
of saving rates to real interest rates, it appears to be more common to think in terms of elasticities. Because the sample mean of $(I / Y)_{w d, t}$ is .23 , while that for $r_{w d, t}^{e}$ is only .020 , the implied elasticities are small; only .03 at the sample means. The calculated elasticities would, however, tend to be substantially greater for net saving rates.

Column 1 of Table 4 shows that the estimated effect of STOCK $_{w d, t-1}$ on the investment-demand ratio is .051 , s.e. $=.010$. Since the sample standard deviation of STOCK $_{w d, t-1}$ is .16 , the result means that a 1 s.d. move in the stock market changes the investment-demand ratio by .008 compared to a sample s.d. for $(I / Y)_{w d, t}$ of .013. The estimated effect of $\mathrm{POIL}_{\mathrm{t}-1}$ on the desired saving rate in col. 2 is -.033 , s.e. $=.006$. Given the sample s.d. for POIL $_{\mathrm{t}-1}$ of .21 , a $1 \mathrm{s.d}$. move in the relative oil price implies a shift in the desired saving rate by .007 .

Columns 1 and 2 show that the estimated effects of the lagged dependent variable, $(I / Y)_{w d, t-1}$, are 1 for the investment-demand ratio (as constrained by the model) and .58 , s.e. $=.08$, for the desired saving rate. The greater persistence of investment demand than of desired saving generates the positive relation in the reduced form between $r_{w d, t}^{e}$ and $(I / Y)_{w d, t-1}$. If the coefficient on $(I / Y)_{w d, t-1}$ in the investment-demand equation is freed up, the estimated value is .93 , s.e. $=.11$. In this case, the estimated coefficient of $(\mathrm{I} / \mathrm{Y})_{\mathrm{wd}, \mathrm{t}-1}$ in the saving-rate equation becomes .55 , s.e. $=.09$. Thus, this unrestricted version of the model does indicate significantly greater persistence in investment demand than in desired saving.

Column 2 shows the positive estimated effect for $D M_{w d, t-1}$ on the desired saving rate $(.183$, s.e. $=.037)$. The previous discussion of the reduced form 
indicated that this estimate stems from the negative relation between $r_{w d, t}^{e}$ and $D M_{w d, t-1}$, and not from any relation between $(I / Y)_{w d, t}$ and $D M_{w d, t-1}$.

Column 4 of Table 4 shows that the estimated effect of the debt-GDP ratio on the desired saving rate is negative but insignificant $(-.026$, s.e. $=$ .015). The cyclically-adjusted deficit variable has a positive and marginally significant estimated effect on desired saving (.144, s.e. = .077). This "wrong" sign accords with the results discussed before in Table 3 ,

$\underline{\text { Simulations for Expected Real Interest Rates and Investment Ratios }}$

Why were expected real interest rates so high in 1981-86?

We can use the estimated model for the expected real interest rate and the investment ratio to assess the frequently-asked question: "why have real interest rates been so high in the 1980s?" We approach this question by comparing the period, 1981-86, during which the average value of $r_{w d, t}^{e}$ was $4.2 \%$, with an earlier reference period of equal length, 1975-80, during which the average of $r_{w d, t}^{e}$ was $0.3 \%$. Hence we seek to explain the increase in the average expected real interest rate from $1975-80$ to $1981-86$ by 3.9 percentage points.

According to the model, the differences in averages of expected real interest rates should be explicable mainly in terms of differences in stock-market returns, oil prices, and monetary growth. Some role would also be played by differences in initial conditions for $r_{w d, t-1}^{e}$ and $(I / Y)_{w d, t-1}$ (in 1981 compared to 1975). Note from Table 5 that the averages for STOCK $_{w d, t-1}$ were $7.7 \%$ in $1981-86$ versus $-6.2 \%$ in $1975-80$, those for POIL ${ }_{t-1}$ were 0.93 in $1981-86$ versus 0.61 in $1975-80$, and those for $D M_{w d, t-1}$ were 
7.91\% in $1981-86$ versus $8.80 \%$ in $1975-80$. The differences in initial conditions were .0245 for $\mathrm{r}_{\mathrm{wd}, \mathrm{t}-1}^{\mathrm{e}}$ in 1981 versus .0061 in 1975 , and .226 for $(\mathrm{I} / \mathrm{Y})_{\mathrm{wd}, \mathrm{t}-1}$ in 1981 versus .249 in 1975 .

We can simulate the estimated model to estimate the extent to which the higher average for $r_{w d, t}^{e}$ in 1981-86 than in 1975-80 can be attributed to differences in STOCK $_{w d, t-1}, \mathrm{POIL}_{t-1}, \mathrm{DM}_{\mathrm{wd}, t-1}$, and the initial conditions for $r_{w d, t-1}^{e}$ and $(I / Y)_{w d, t-1}$. We consider the restricted version of the joint model as reported in Table 4 and also the unrestricted version that does not impose the overidentifying restrictions from the structure. We also neglect any interplay among STOCK $_{w d, t}, \mathrm{POIL}_{t}$, and $D M_{w d, t}$; that is, we treat the time paths of these three variables as exogenous.19

Given the actual time paths for STOCK $w d, t, \mathrm{POIL}_{t}$, and $D M_{w d, t}$, and the actual values for $r_{w d, t-1}^{e}$ and $(I / Y)_{w d, t-1}$ in 1981 and 1975 , dynamic simulations of the restricted model for 1981-86 and 1975-80 predict an increase in the average of $r_{w d, t}^{e}$ of 3.8 percentage points compared to the actual increase of 3.9 points (see the columns labeled "simulated total" and "actual" in section I of Table 5). We then dynamically simulated the restricted model for 1981-86 with the values of STOCK $_{w d, t-1}$ from 1975-80 substituted year by year for those in 1981-86. This simulation implied that

19 We do find a significant negative relation between stock returns for year $t$ and the change in oil prices during year t. Also, M1 growth has significant negative reactions to the contemporaneous change in oil prices and to lagged stock returns. We can filter the stock returns to compute the component exogenous to oil-price changes, and we can filter M1 growth to calculate the part exogenous to oil-price changes and lagged stock returns. In the discussion below we attribute changes in expected real interest rates and investment ratios to the behavior of stock returns, oil prices, and monetary growth. The breakdown among these three variables would change if we shifted from gross numbers to the filtered values. 
2.5 percentage points of the increase in the average of $r_{w d, t}^{e}$ from 1975-80 to 1981-86 derived from the higher average for stock returns in the latter period (see the column labeled "STOCK" in the table).20 Similarly, we found that 1.9 percentage points of the rise in the average of $r_{w d, t}^{e}$ resulted from the increase in average oil prices (the column "POIL"), 0.3 points from the lower average monetary growth (the column "DM"), and -0.9 points from the differences in initial conditions. The main change in the initial conditions is the much lower value for $(I / Y)_{w d, t-1}$ in 1981 than in 1975 ; this effect by itself would have lowered real interest rates for 1981-86. The results from simulations of the unrestricted model, shown in Table 5 , are basically similar.

Table 5 also indicates the simulated results for investment ratios. The restricted model predicts that the average of $(I / Y)_{w d, t}$ for 1981-86 would be 0.9 percentage points below the average for 1975-80, compared to the actual shortfall of 1.1 points. The simulations attribute 0.9 percentage points of the decline in the average investment ratio to higher oil prices, -1.4 points to the more favorable stock returns (which, by themselves, would have raised the investment ratio), 0.2 points to lower monetary growth, and 1.2 points to differences in initial conditions. The main element in the initial conditions is again the lower value for $(\mathrm{I} / \mathrm{Y})_{\mathrm{wd}, \mathrm{t}-1}$ in 1981 than in 1975. The results from the unrestricted model are again similar.

20 The results depend not only on differences in the average value of STOCK $_{w d, t-1}$, but also on differences in the time pattern. It is possible for the simulated effects to go in the direction opposite to that suggested just from a comparison of means. 
Why were expected real interest rates so low in 1975-80?

We now compare the low average for $r_{w d, t}^{e}$ in $1975-80,0.3 \%$, with the higher value, $2.5 \%$, that prevailed during an earlier reference period of the same length, 1965-70. (The results are similar if we pick alternative six-year reference periods in the 1960s or early 1970s.) Section II of Table 5 shows that simulations of the restricted model predict a decline of only 1.3 percentage points in the average of $r_{w d, t}^{e}$ from 1965- 70 to 1975-80 compared with the actual decrease of 2.2 points. The model attributes 1.8 percentage points of the decline to lower stock returns, - 1.1 points to higher oil prices (which, by themselves, would have raised expected real interest rates), 0.7 points to higher monetary growth, and -0.1 points to differences in initial conditions. The results from the uncestricted model are similar.

Overall, the largest factor behind the differences in expected real interest rates among the three periods, 1965-70, 1975-80, and 1981-86, is the variation in stock returns. The fall in real interest rates from 1965-70 to 1975-80 goes along with a worsening of stock returns (from 0.9\% to -6.2\%), and the steep rise in rates in 1981-86 reflects sharply higher stock returns (7.7\%). The movements in oil prices are also important, although higher oil prices in 1975-80 compared to $1965-70$ partially counteract the movement to lower real interest rates. The increase in oil price in 1981-86 compared to 1975-80 reinforces the stock market in generating a shift toward higher real interest rates. 
Why did expected real interest rates fall in 1987-88 and rise in 1989?

The average of $r_{w d, t}^{e}$ fell by 1.7 percentage points from 1985-86 to 1987-88 and then rose by 1.1 percentage points from 1988 to 1989 . Sections III and IV of Table 5 contain simulations for these periods. The dominant factor behind the decline in real interest rates in 1987-88 is the fall in oil prices. The main element underlying the rise in real rates in 1989 is the much more favorable stock return in 1988 (15.0\%) compared to 1987 $(-8.2 \%)$.

We have assembled nearly complete data for 1989 on the variables STOCK $_{w d, t}, \mathrm{POIL}_{t}, \mathrm{DM}_{w d, t},(I / Y)_{w d, t}$, and $r_{w d, t}^{e}$. Using these values, we can use the model to forecast the expected real interest rate and investment ratio for 1990. Remarkably, the restricted model implies a predicted value for $r_{w d, t}^{e}$ of $5.6 \%$ (5.5\% from the unrestricted model). The forecast from the restricted model for 1990 not only constitutes an increase by 2.1 percentage points in $r_{w d, t}^{e}$ from the value prevailing in 1989 , it also represents a level that is almost a full percentage point above the highest value of the entire previous sample, 1958-89. The five determinants of $r_{w d, t}^{e}$ in the model turn out all to point in the direction of higher real interest rates in 1990: the favorable stock return (17.4\% in 1989 versus $14.8 \%$ in 1988) accounts for 0.1 percentage point, the increase in oil prices (.525 versus .406$)$ for 0.5 percentage point, reduced monetary growth (3.2\% versus $6.6 \%$ ) for 0.8 percentage point, and the change in initial conditions (the rise in $(I / Y)_{w d, t}$ from .242 in 1988 to .247 in 1989 and the increase in $r_{w d, t}^{e}$ from .023 in 1988 to .035 in 1989) accounts for 0.9 percentage point. Needless to say, this prediction of a rise in the expected real interest rate to a range not seen at least in the last thirty years will provide a severe test of the model. 
With respect to the investment ratio, the restricted model predicts little change from 1989 (.246 in 1990 versus .247 in 1989), whereas the unrestricted model projects an increase by 0.3 percentage point.

Given the stress on fluctuations in the stock market, we would like to know what fundamental factors underlie these fluctuations. (We would, of course, also like to understand the forces that lead to changes in oil prices and monetary growth.) We interpret stock returns as reflecting changes in the expected profitability of investment, $\mathrm{PROF}_{t}^{\mathrm{e}}$, and in the risk premium, $\rho_{t}$. We plan to use data on actual profitability to separate the influences from these two channels. At this point, we can only note that the fluctuations in stock prices could derive from technological innovations, changing conditions of labor markets or international competition, shifts in government policies with regard to taxation and regulation, and so on. Although we have not isolated the main forces that influence stock returns, the findings suggest that these forces are crucial for the determination of expected real interest rates and investment ratios.

\section{Systems for Individual Countries' Expected Real Interest Rates}

In the world model with an integrated capital market, "the" expected real interest rate depends on world variables, which include world aggregates of stock returns and monetary growth and the world price of oil. Thus, the reduced form in equation (7) gives an expression for $r_{t}^{e}$ in terms of these world variables. In practice, we observe individual time series, $r_{i t}^{e}$, for each country $i$. In the previous analys is we combined these observations into a world index, $r_{w d, t}^{e}$, that gives more weight to countries with higher shares 
in world real GDP. Then we related this world index to the world influences suggested by the structural model.

We can think of each country's expected real interest rate as determined by the hypothetical world rate-which depends on world variables in the manner suggested by the structural model-plus some own-country factors. That is,

$$
r_{i t}^{e}=r_{t}^{e}+x_{i t}
$$

where $x_{i t}$ represents variables particular to country $i$ and $r_{t}^{e}$ depends on the world variables as in the previous analysis. Unless the $x_{i t}$ are random errors that are perfectly correlated across the countries, we would get more efficient estimates of the determinants of $r_{t}^{e}$ by using all the individual observations on the $r_{i t}^{e}$ for the nine countries, instead of combining everything into the world weighted average, $r_{w d, t}^{e}$. That is, we can think of equation (11) as a system of nine equations, and we can estimate the variance-covariance structure of the error terms, $x_{i t}$, along with the estimation of the coefficients for the variables that determine $r_{t}^{e}$.

When we look empirically at the values of $r_{i t}^{e}$ for an individual country, we typically find a good deal of serial persistence about the rate, $r_{t}^{e}$, that can be explained by worldwide forces. We can allow for this effect more or less equivalently by including $r_{i, t-1}^{e}$ as an element of $x_{i t}$ or by treating $x_{i t}$ as an error term that is serially correlated. Because it is simpler in the systems discussed below and also delivers somewhat better fits (at least relative to an $A R(1)$ model for the $x_{i t}$ ), we take the approach of including 
$\mathrm{r}_{\mathrm{i}, \mathrm{t}-1}^{\mathrm{e}}$ as a regressor. ${ }^{21}$ We do not make any structural interpretations for the statistical significance of this lagged dependent variable. It could reflect a variety of own-country forces that we do not hold constant, including serially-correlated measurement error in nominal interest rates or expected inflation and persisting differences across countries in riskiness of real returns or the tax treatment of these returns.

If the world capital and goods markets are fully integrated, shifts to a single country's investment demand or desired saving affect the expected real interest rate only to the extent that these shifts affect the world aggregate of investment demand or desired saving. Therefore, own-country variables like country i's stock return and monetary growth would matter for $r_{i t}^{e}$ only to the extent that they contribute to the world aggregates of stock returns and monetary growth. With the world variables held constant, the importance of these own-country variables for $r_{i t}^{e}$ will provide some evidence about the extent of country i's integration into world markets. If the own-country variables are unimportant for country $i$, we cannot conclude unambiguously that country $i$ is well integrated. That is, country i could be isolated from the rest of the world, but $r_{i t}^{e}$ may nevertheless be insensitive to the own-country explanatory variables that we consider. He get clearer evidence from observations in the reverse direction. If $r_{i t}^{e}$ depends in an important way on the own-country variables for country $i$, then we have an indication that the country is not well integrated into world markets.

\footnotetext{
$210 \mathrm{nce}$ we hold fixed $\mathrm{r}_{\mathrm{i}, \mathrm{t}-1}^{\mathrm{e}}$, the determinants of $\mathrm{r}_{\mathrm{t}-1}^{\mathrm{e}}$ (which are second lags of the world variables) are insignificant in the equations for $r_{i t}^{e}$.
} 
Table 6 contains system estimates for $r_{i t}^{e}$ for $n$ ine countries over 1959-88. The estimation is by generalized least squares, which allows for estimation of each country's error variance and of contemporaneous covariances across the countries. Roughly speaking, the method of estimation differs from that in Table 2 in that the weight for each country now depends mainly on the estimated error variance, rather than on the relative GDP.

We begin with a model that, aside from $r_{i, t-1}^{e}$ and individual constants for each country, includes only the world variables that we considered before; $\mathrm{STOCK}_{w d, t-1}, \mathrm{POIL}_{\mathrm{t}-1},(\mathrm{I} / \mathrm{Y})_{\mathrm{wd}, \mathrm{t}-1}$, and $\mathrm{DM}{ }_{\mathrm{wd}, \mathrm{t}-1}$. These results are in column 1 of Table 6 . The estimated coefficients on each of the independent variables, including the lagged dependent variable, are constrained to be the same for each country. In this form, the estimates are similar to those from the comparable equation for $r_{w d, t}^{e}$ (Table 2, col. 2). The main difference (with the increase in the overall number of observations from 30 to 270 ) is the reduction in the standard errors for the estimated coefficients.

Column 2 of Table 6 adds three own-country variables: STOCK $_{i, t-1}$, $(\mathrm{I} / \mathrm{Y})_{\mathrm{i}, \mathrm{t}-1}$, and $\mathrm{DM} \mathrm{i}_{\mathrm{t}-1}$. (We assume that $\mathrm{POIL}_{\mathrm{t}-1}$ takes on the same value for each country; therefore, we cannot distinguish world from own-country values in this case.) We constrain the coefficients of the three own variables to be the same across the nine countries. In this form, a test of the hypothesis that the coefficients on the three own-country variables are all zero leads to the likelihood-ratio statistic 2.7 compared to the $5 \%$ critical value of 7.8. Thus, we accept the hypothesis that own-country expected real interest rates depend on the world variables and not on the own-country 
variables (aside from the individual constant and the lagged dependent variable).

Column 3 of Table 6 retains the three own-country variables added in column 2 , but deletes the corresponding three world variables, STOCK $w d, t-1$, $(I / Y)_{w d, t-1}$, and $D M_{w d, t-1}$. A test of the hypothesis that the coefficients of these three world variables are all zero leads to the likelihood-ratio statistic 27.8 compared to the $5 \%$ critical value of 7.8 . Therefore, the data reject the hypothesis that own-country expected real interest rates depend on the own-country variables and not on the world variables.

Overall, the results in columns 1-3 provide evidence that individual country expected real interest rates depend more on worldwide forces than on own-country forces. In this sense, the results suggest that the nine OECD countries were operating to a considerable extent on integrated world markets. Note, however, that the results presented thus far apply when all countries are constrained to have the same coefficients on the world and own-country variables (aside from an individual constant term).

We tested whether the system regression in Table 5, col. 1 was stable over the periods 1959-72 and 1973-88. The test for equality of coefficients over the two samples is accepted (likelihood-ratio statistic of $8.8,5 \%$ critical value with 14 restrictions of 23.7.).

Column 4 of Table 6 constrains the constant terms to be the same across the countries. The hypothesis of equality is strongly rejected: the likelihood-ratio statistic is 48.1 compared to a $5 \%$ critical value of 15.5 . In this sense, we confirm the general belief that the average levels of expected real interest rates differed significantly across the nine countries. 
Columns 5 and 6 of the table add the world fiscal variables, which we considered before. The results are similar to those found for the world real interest rate in Table 2: the debt variable is insignificant, the unadjusted deficit variable is significantly negative $(-.23$, s.e. $=.07$ in Table 5 , col. $5)$, and the cyclically-adjusted deficit variable is insignificant (col.6).

Column 7 of Table 6 uses nominal interest rates, $R_{i t}$, as dependent variables and adds the expected inflation rate, $\pi_{i t}^{e}$, on the right side. The estimated coefficient on $x_{i t}^{e}$ (constrained to be the same across the countries) is now significantly less than one: .562 , s.e. $=.034$. To some extent, this result is sensitive to the U.K. data, which exhibit sharply negative values for $r_{i t}^{e}$ in the mid 1970s. If the U.K. is allowed to have its own coefficient on $\pi_{u k, t}^{e}$, the estimated coefficient on $\pi_{u k, t}^{e}$ is .42 , s.e. $=$ .05 , and that on $\pi_{i t}^{\mathrm{e}}$ for the other eight countries rises to .68 , s.e. $=.04$. Our conjecture is that the departure of this estimated coefficient from unity reflects measurement error in the construction of expected inflation.

Columns 1 and 2 of Table 7 provide statistics $\left(R^{2}\right.$ and $\left.\hat{\sigma}\right)$ for the individual countries for the system regression from Table 6, col. 1. Note that the model explains virtually none of the variations in expected real interest rates for Japan. For the U.K., the high value of $\hat{\sigma}$ seems to reflect mainly the large negative numbers for $\mathrm{r}_{\mathrm{uk}, \mathrm{t}}^{\mathrm{e}}$ in the mid 1970s. The model cannot explain these values; a finding that is reasonable if these observations reflect incorrect estimates of $\pi_{\mathrm{uk}, t}^{\mathrm{e}}$.

We tested the hypothesis that the nine countries have the same coefficients on the four world variables, STOCK $_{w d, t-1}, \mathrm{POIL}_{t-1},(\mathrm{I} / \mathrm{Y})_{\mathrm{wd}, t-1}$, and $D M_{w d, t-1}$, and the lagged dependent variable, $r_{i, t-1}^{e}$. If we relax this restriction for one country at a time (with the other eight still restricted 
to have equal coefficients), we get the likelihood-ratio statistics shown in column 3 of Table 7 . At the $5 \%$ critical level (with 5 restrictions), the hypothesis of equality is rejected for only two countries, Canada and Germany. For Canada, the main reason for rejection is that, unlike the other countries, the unrestricted coefficient estimate for the lagged dependent variable is close to zero $(-.05$, s.e. $=.08)$.

An overall test for equality of coefficients across the nine countries (40 restrictions) leads to the likelihood-ratio statistic of 83.1 compared to the $5 \%$ critical value of 55.5 . Thus, the model fails to pass the test that each country's expected real interest rate reacts in the same way to the four world variables and the lagged dependent variable. Columns 4 and 5 of Table 7 show the fit statistics $\left(R^{2}\right.$ and $\hat{\sigma}$ ) for each country in the unrestricted form. The largest changes from columns 1 and 2 (Canada, Germany, Japan, and the U.K.) correspond to the likelihood-ratio statistics shown in column 3 .

We also allowed each country to depend in an individual way on its own variables. We constrained the coefficients on the world variables and the lagged dependent variable to be the same across the countries, but we allowed country $i$ to have its own coefficients on the three variables: STOCK $_{i, t-1}$ STOCK $_{w d, t-1},(I / Y)_{i, t-1}-(I / Y)_{w d, t-1}$, and $D M_{i, t-1}-D M_{w d, t-1}$. By entering these variables as deviations from their world counterparts we constrained each country to react in the same way to equal changes in world and own variables; for example, to an equal increase in STOCK $_{w d, t-1}$ and STOCK $_{i, t-1}$. But we allowed $r_{i, t}^{e}$ to react in an individual way to a shift in the own-country variable, say STOCK $_{i, t-1}$, for a given value of the world variable. Presumably, the more a country is isolated from world markets the greater will tend to be the reaction of $r_{i t}^{e}$ to the own variables. 
We first introduced the own-country variables for one country at a time. 0wn variables (except for the constant and the lagged dependent variable) were excluded for the other eight countries. (Recall that the coefficients of the world variables and of the lagged dependent variable were constrained to be equal for all nine countries.) Column 6 of Table 7 shows likelihoodratio statistics for tests of the hypothesis that the coefficients of the three own-country variables are all zero. We accept this hypothes is at the 5\% critical level for all countries except Japan and the U.K. Thus, the results suggest that these two countries were particularly isolated (for at least part of the sample) from international markets.

We also introduced the three own-country variables simultaneously for all nine countries. Individual coefficients on these variables were estimated for each country. An overall tesi that all of these coefficients were zero (27 restrictions) led to the likelihood-ratio statistic 74.4 compared to the 5\% critical value of 40.1 . Thus, the model fails to pass the test that own-country expected real interest rates are unresponsive in an individual way to own-country variables (given common reactions to world variables and the lagged dependent variable). Columns 7 and 8 of Table 7 show fit statistics $\left(\mathbb{R}^{2}\right.$ and $\hat{\sigma}$ ) for each country in the model that allows individual coefficients for all countries on the three own variables. The largest changes from columns 1 and 2 (Japan and the U.K.) correspond to the likelihood-ratio statistics shown in column 6 .

\section{Systems for Individual Countries' Investment Ratios}

We now relate the investment ratio for each of the ten countries, $(I / Y)_{i t}$, to world and own-country variables. Unlike for the expected real 
interest rate, $r_{i t}^{e}$, the null hypothesis under integrated world markets is not that $(I / Y)_{i t}$ depends only on world variables. $(I / Y)_{i t}$ would depend on any variable that influences own-country investment demand-notably, the own- country stock return, STOCK $_{i, t-1}$, and the lagged investment ratio,

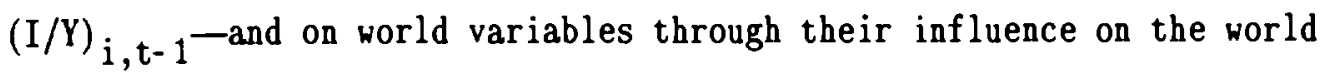
expected real interest rate. Given the world variables (and hence the world expected real interest rate), (I/Y) it would be independent of influences on country i's desired saving rate. Because $\mathrm{POIL}_{t-1}$ is a common influence across countries, the only variable of this type in the previous analysis was own-country monetary growth, $\mathrm{DM}_{\mathrm{i}, \mathrm{t}-1}$. (The own-country fiscal variables would also be in this category, but the fiscal variables were found to be unimportant in general.)

Table 8 shows the results for $(I / Y)_{i t}$ for the ten-country system of investment ratios over the period 1959-88. The independent variables are POIL $_{t-1}$; the world and own-country lagged values of STOCK, (I/Y), and DM; $r_{w d, t-1}^{e} ;^{22}$ and individual constant terms. The regression in column 1 shows a significant, positive effect for STOCK $_{i, t-1}(.017$, s.e. $=.003)$. This result can be interpreted as an effect from changes in the expected profitability of investment in country $i$ (or possibly changes in the risk premium applicable to these investments). On the other hand, the estimated coefficient of STOCK $_{w d, t-1}$ is also positive: .017 , s.e. $=.008$. If the own-country stock

22 Because the expected real interest rate is unavailable for Italy we entered $r_{w d, t-1}^{e}$ for each country. The results change little if we also include $r_{i, t-1}^{e}$ in the nine-country system that excludes Italy. That is, lags of expected real interest rates are unimportant in general for the investment ratios. 
return holds constant the expected profitability of investment (risk-adjusted), then the world stock return would influence (I/Y) it only through its effect on world expected real interest rates; that is, the effect of STOCK $_{w d, t-1}$ on $(I / Y)_{i t}$ would be negative. It is possible, however, that stock returns in other countries provide information about the profitability of investment in country $i$, even for a given value of country i's stock return.23 This outcome might arise if ownership extends across countries or if the stock-price data for some countries are poor measures of the expected profitability of investment in those countries.

As in previous results, the regression in Table 8 , col. 1 indicates a significantly negative effect of $\mathrm{POIL}_{t-1}$ on the investment ratios $(-.020$, s.e. $=.006)$. One puzzle is that the estimated coefficient for own-country monetary growth, $D M_{i, t-1}$, is significantly positive $(.039$, s.e. $=.010)$, whereas that on world monetary growth, $D M_{w d, t-1}$, is negative but insignificant $(-.049$, s.e. $=.042)$. We found before an inverse relation between $\mathrm{r}_{\mathrm{it}}^{\mathrm{e}}$ and the lag of world monetary growth, not own-country monetary growth (Table 6, col. 2). Thus, the interest-rate effects suggest a positive connection between $D M_{W d, t-1}$ and $(I / Y)_{i t}$, but the results indicate instead a positive coefficient on $D M_{i, t-1}$. (Recall that, for the world variables in Table $3, D M_{w d, t-1}$ had an insignificant effect on $\left.(I / Y)_{w d, t} \cdot\right)$ There may be an endogenous-money story to explain these results, but we have not yet come up with it.

${ }^{23} \mathrm{As}$ a related matter, Barro (1990) finds that Canadian investment responds more to the U.S. stock market than to the Canadian stock market. 
Column 2 of Table 8 eliminates three world variables from the regression: STOCK $_{w d, t-1},(I / Y)_{w d, t-1}$, and $D M_{w d, t-1}$. Theoretically (abstracting from the possible informational role of world stock prices for own-country profitability), these variables would affect $(I / Y)_{\text {it }}$ only through their effects on the world expected real interest rate. The three world variables turn out to be jointly insignificant; the likelihood-ratio statistic is 2.9 compared to the $5 \%$ critical value of 7.8 .

It would be possible to consider the system of equations for investment ratios jointly with the system for expected real interest rates. The restrictions imposed by the structural model could be imposed on this overall joint system. We plan eventually to undertake this grand system estimation.

\section{Summary of Main Results}

We thought of the expected real interest rate for the major industrialized countries as determined by the equation of aggregate investment demand to the aggregate of desired national saving. We used stock-market returns to isolate shifts to expected profitability of investment (or risk premia) and hence to investment demand. We used oil prices to capture shifts to temporary income and hence to desired national saving. In some models, monetary expansion would appear as a positive shock to desired national saving, and in others, fiscal expansion would enter as a negat ive shock.

We used the structural model to determine a reduced form for the "world" expected real interest rate and ratio of investment to GDP. The main predictions are that more favorable stock returns raise the real interest rate and investment, higher oil prices increase the real interest rate but 
decrease investment, higher monetary growth lowers the real interest rate and stimulates investment, and greater fiscal expansion raises the real interest rate and reduces investment.

We estimated the reduced form of the model on data for ten OECD countries over the period 1959-88. Thus far, the results pertain to annual data on short-term interest rates. (Because of data problems with Italy we included only nine countries in the equations for interest rates.) The results for world (GDP-weighted) expected real interest rates reveal significant effects in the predicted directions for world stock returns, oil prices, and world monetary growth. Fiscal variables turned out to be unimportant. The behavior of the world investment ratio was also consistent with the model, except that the hypothesized positive effect from monetary growth did not show up and fiscal variables were unimportant.

Estimates of the reduced form that were constrained by the structural restrictions led to estimates of structural coefficients, such as the responsiveness of desired national saving rates to the expected real interest rate. We $f$ ind that an increase in the expected real interest rate by one percentage point raises the desired saving rate by about one-third of a percentage point.

We simulated the model to try to explain why expected real interest rates were high for 1981-86 (averaging 4.27) and low for 1975-80 (averaging 0.37). The dominant influence was the variation in stock returns; these returns were very low for 1974-79 and much higher for 1980-85. The increase in oil prices from the early 1970s until 1986 is also an important factor. We attributed the drop in expected real interest rates for 1987-88 (to an average of 2.3\%) mainly to the decline in oil prices, and the rise in the rate for 1989 (to 
3.57) mainly to the improved stock market in 1988. The model also forecasts a dramatic rise in the expected real interest rate to $5.6 \%$ in 1990 . This value is almost a full percentage point above the highest value that occurred during the period 1958-89.

We estimated systems of equations for expected real interest rates for nine OECD countries. (We also estimated systems of equations for investment ratios for ten OECD countries, including Italy.) These systems include world and own-country variables as regressors. One finding is that each country's expected real interest rate depends primarily on world factors, thereby suggesting a good deal of integration of world markets. We do find, however, significant effects of own-country variables for Japan and the U.K. Our interpretation is that these countries were significantly isolated from international markets, at least over part of the period 1959-88.

The research carried out thus far suggests a number of avenues for future work. The possibilities that we are presently pursuing are the analys is of longer term interest rates, the inclusion of measures of the profitability of investment, the addition of variables such as defense expenditures that represent exogenous shifts to desired saving, consideration of tax effects related to interest income and expenses, and the estimation of equations for expected real interest rates and investment ratios with quarterly data. We are also considering a division of investment into components that would be especially sensitive to the stock market (business non-residential investment) and those that would be less sensitive (residential investment, public investment, and purchases of consumer durables). Finally, we are looking into the possibilities for adding more countries; Switzerland and 
Australia appear to be the most promising in terms of the availability of data. 


\section{References}

Barro, R.J., "Intertemporal Substitution and the Business Cycle," CarnegieRochester Conference Series on Public Policy, 14, Spring 1981, 237-268. ........... Vacroeconomics, third edition, Wiley, New York, 1989.

.......... "The Stock Market and Investment," The Review of Financial Studies, spring 1990.

Blanchard, 0.J., "Debt, Deficits, and Finite Horizons," Joxrnal of Political Economy, 93, April 1985, 223-247.

............... and Lummers, "Perspectives on High World Real Interest

Rates," Brookings Papers on Economic Activity, no. 2, 1984, 273-324.

Evans, P., "Do Budget Deficits Raise Nominal Interest Rates? Evidence from Six Countries," Journal of Monetary Economics, 20, September 1987, 281-300.

Fama, E.F., "Stock Returns, Real Activity, Inflation, and Money," American Economic Review, 71, September 1981, 545-565.

Hayashi, F., "Tobin's Marginal q and Average q: a Neoclassical

Interpretation," Econometrica, 50, January 1982, 213-224.

Mishkin, F.S., "Are Real Interest Rates Equal Across Countries? An Empirical Investigation of International Parity Conditions," Journal of Finance, 39, December 1984, 1345-1357.

Mundell, R.A., "Infiation, Saving, and the Real Rate of Interest," in R.A.

Mundell, Monetary Theory, Goodyear, Pacific Palisades CA, 1971.

Plosser, C.I., "Fiscal Policy and the Term Structure," Jozrnal of Monetary Economics, 20, September 1987, 343-367. 
Summers, R. and A. Heston, "A New Set of International Comparisons of Real Product and Price Levels" Estimates for 130 Countries," The Review of Income and Kealth, 34, March 1988, 1-25. 
Table 1

Means and Standard Deviations of Main Variables, 1959-88

$\begin{array}{lcc}\text { Variable } & \text { Mean } & \text { Standard Deviation } \\ \mathrm{R}_{\mathrm{wd}, \mathrm{t}} & .066 & .024 \\ \boldsymbol{\pi}_{\mathrm{wd}, \mathrm{t}} & .049 & .030 \\ \mathrm{r}_{\mathrm{wd}, \mathrm{t}} & .017 & .024 \\ \pi_{\mathrm{wd}, \mathrm{t}}^{\mathrm{e}} & .046 & .022 \\ \mathrm{r}_{\mathrm{wd}, \mathrm{t}}^{\mathrm{e}} & .020 & .015 \\ (\mathrm{I} / \mathrm{Y})_{w d, t} & & \\ \text { STOCK }_{w d, t-1} & .234 & .013 \\ \text { POIL }_{\mathrm{t}-1} & .022 & .158 \\ \text { DM }_{\mathrm{wd}, \mathrm{t}-1} & .560 & .209 \\ \text { RDEBTY }_{\text {wd }, \mathrm{t}-1} & .080 & .022 \\ \text { RDEFY }_{w d, t-1} & .341 & .076 \\ \text { RDEFYA }_{w d, t-1} & .013 & .017 \\ & .000 & .010\end{array}$

Own-Country Variables

\begin{tabular}{lcccccc} 
Country & \multicolumn{2}{c}{ WT ${ }_{\text {it }}$} & \multicolumn{2}{c}{$\mathrm{r}_{\text {it }}^{\mathrm{e}}$} & \multicolumn{2}{c}{$(\mathrm{I} / \mathrm{Y})$ it } \\
& mean & stnd dev & mean & stnd dev & mean & stnd dev \\
BE & & & & & & \\
CA & .0147 & .0004 & .0414 & .0143 & .2151 & .0296 \\
FR & .0433 & .0019 & .0283 & .0206 & .2279 & .0137 \\
GE & .0815 & .0038 & .0163 & .0208 & .2401 & .0247 \\
IT & .1002 & .0038 & .0311 & .0197 & .2444 & .0304 \\
& .0621 & .0019 &.- &.- & .2765 & .0377 \\
JA & .1315 & .0305 & .0199 & .0190 & .3183 & .0422 \\
NE & .0202 & .0009 & .0102 & .0195 & .2396 & .0344 \\
SW & .0131 & .0010 & .0178 & .0243 & .2222 & .0286 \\
UK & .0806 & .0081 & .0124 & .0348 & .1951 & .0187 \\
US & .4528 & .0247 & .0198 & .0197 & .2057 & .0129
\end{tabular}


Table 1, continued

\begin{tabular}{lcccc} 
Country & \multicolumn{2}{c}{ STOCK $_{\mathrm{i}, \mathrm{t}-1}$} & \multicolumn{2}{c}{$\mathrm{DH}_{\mathrm{i}} \mathrm{t}-1$} \\
mean & stnd dev & & stnd dev \\
BE & & & & \\
CA & -.0115 & .1711 & .0568 & .0405 \\
FR & .0121 & .1608 & .0926 & .0778 \\
GE & -.0125 & .2322 & .0974 & .0427 \\
IT & .0322 & .2479 & .0789 & .0400 \\
JA & -.0205 & .2891 & .1424 & .0447 \\
NE & .0701 & .2095 & .1266 & .0780 \\
SW & .0096 & .2114 & .0813 & .0429 \\
UK & .0405 & .2038 & .0843 & .0495 \\
US & .0239 & .2928 & .0913 & .0676 \\
& .0178 & .1715 & .0570 & .0315
\end{tabular}

Note: See Table A2 for definitions and sources of the variables. 
Table 2

Regressions for World Expected Real Interest Rate

(3)

(4)

(5)

(6)

Constant

$$
\begin{aligned}
& -.059 \\
& (.038)
\end{aligned}
$$

$-.129$

$-.137$

$-.130$

$\begin{array}{ll}-.044 & -.131 \\ (.305) & (.052)\end{array}$

STOCK $_{w d, t-1}$

.064
$(.009)$

.063
$(.009)$

.063
$(.010)$

.061
$(.010)$

$\begin{array}{ll}.047 & .064 \\ (.028) & (.014)\end{array}$

$\mathrm{POIL}_{\mathrm{t}-1}$

.029
$(.009)$

.039
$(.007)$

.050
$(.010)$

.044
$(.009)$

.050

$\begin{array}{ll}-.062 & .047 \\ (.418) & (.013)\end{array}$

$(I / Y)_{w d, t-1}$

.220
$(.150)$

.487
$(.124$

.502

.577

.585
$(.148)$

.418
$(.629)$

.555

$r_{w d, t-1}^{e}$

$\begin{array}{ll}.581 & .518 \\ (.101) & (.075)\end{array}$

$\begin{array}{ll}.471 & .476 \\ (.092) & (.099)\end{array}$

.433
$(.103)$

$.277 \quad .510$

$\mathrm{DM}_{\mathrm{Hd}, \mathrm{t}-1}$

-.251
$(.054)$

$-.168 \quad-.240$

$-.239$

(.386)

(.103)

$\operatorname{RDEBTY}_{w d, t-1}$

-.

.029
$(.026)$

(.063)

(.054)

$\begin{array}{ll}-.240 & -.212 \\ (.132) & (.106)\end{array}$

RDEFY $_{w d, t-1}$

$-$

$-$

$-.191$

(.118)

RDEFYA $_{w d, t-1}$

$-$

$-$

-.

$-.015$

.021
$(.027)$

$\pi_{w d, t-1}^{e}$

$\mathrm{R}^{2}$

$-$

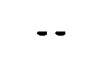

$-$

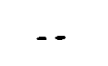

$(.894)$

$\begin{array}{ll}.79 & .89 \\ .0074 & .0054 \\ 1.4 & 1.8\end{array}$

.91

.89

.0053

.0056

.96

.63

.93

DW

1.4

1.8

1.8

1.8

1.2

.0063

Note: Standard errors are in parentheses. $\dot{\sigma}$ is the standard error of estimate (adjusted for degrees of freedom) and DW is the Durbin-Watson Statistic. The dependent variable in cols. $1-4,6,7$ is $r_{w d, t}^{e}$. In col. 5 it is the nominal interest rate, $\mathbb{R}_{w d, t}$. The sample period is $1959-88$ in cols. $1-5$. It is $1959-72$ in col. 6 and 1973-88 in col. 7 . 
Table 3

Regressions for World Investment Ratio

(1)

(2)

(3)

(4)

(5)

(6)

\begin{tabular}{|c|c|c|c|c|c|c|}
\hline Constant & $\begin{array}{l}.053 \\
(.031)\end{array}$ & $\begin{array}{l}.057 \\
(.033)\end{array}$ & $\begin{array}{l}.066 \\
(.051)\end{array}$ & $\begin{array}{l}.076 \\
(.051)\end{array}$ & $\begin{array}{l}-.016 \\
(.125)\end{array}$ & $\begin{array}{l}.133 \\
(.059)\end{array}$ \\
\hline $\mathrm{STOCK}_{w d, t-1}$ & $\begin{array}{l}.036 \\
(.009)\end{array}$ & $\begin{array}{l}.034 \\
(.011)\end{array}$ & $\begin{array}{l}.034 \\
(.010)\end{array}$ & $\begin{array}{l}.031 \\
(.010)\end{array}$ & $\begin{array}{l}.018 \\
(.011)\end{array}$ & $\begin{array}{l}.045 \\
(.016)\end{array}$ \\
\hline $\mathrm{POIL}_{\mathrm{t}-1}$ & $\begin{array}{l}-.016 \\
(.008)\end{array}$ & $\begin{array}{l}-.017 \\
(.008)\end{array}$ & $\begin{array}{l}-.030 \\
(.010)\end{array}$ & $\begin{array}{l}-.020 \\
(.009)\end{array}$ & $\begin{array}{l}.077 \\
(.172)\end{array}$ & $\begin{array}{l}-.033 \\
(.015)\end{array}$ \\
\hline$(I / Y)_{w d, t-1}$ & $\begin{array}{l}.814 \\
(.122)\end{array}$ & $\begin{array}{l}.791 \\
(.139)\end{array}$ & $\begin{array}{l}.848 \\
(.183)\end{array}$ & $\begin{array}{l}.770 \\
(.181)\end{array}$ & $\begin{array}{l}.92 \\
(.26)\end{array}$ & $\begin{array}{l}.57 \\
(.23)\end{array}$ \\
\hline$r_{w d, t-1}^{e}$ & $\begin{array}{l}-.005 \\
(.082)\end{array}$ & $\begin{array}{l}.000 \\
(.085)\end{array}$ & $\begin{array}{l}.037 \\
(.097)\end{array}$ & $\begin{array}{l}-.011 \\
(.101)\end{array}$ & $\begin{array}{l}.043 \\
(.158)\end{array}$ & $\begin{array}{l}-.057 \\
(.118)\end{array}$ \\
\hline$D M_{w d, t-1}$ & -- & $\begin{array}{l}.022 \\
(.060)\end{array}$ & $\begin{array}{l}-.104 \\
(.075)\end{array}$ & $\begin{array}{l}-.049 \\
(.064)\end{array}$ & $\begin{array}{l}.064 \\
(.054)\end{array}$ & $\begin{array}{l}-.127 \\
(.122)\end{array}$ \\
\hline RDEBTY $_{w d, t-1}$ & - & -- & $\begin{array}{l}-.029 \\
(.027)\end{array}$ & $\begin{array}{l}-.021 \\
(.027)\end{array}$ & -- & - \\
\hline $\mathrm{RDEFY}_{w d, t-1}$ & - & -- & $\begin{array}{l}.306 \\
(.125)\end{array}$ & - & -- & - \\
\hline RDEFYA $_{w d, t-1}$ & $\cdots$ & -- & -- & $\begin{array}{l}.331 \\
(.148)\end{array}$ & -- & -- \\
\hline $\mathrm{R}^{2}$ & .82 & .82 & .86 & .86 & .97 & .82 \\
\hline$\hat{\sigma}$ & .0060 & .0061 & .0056 & .0057 & .0023 & .0073 \\
\hline DW & 1.6 & 1.7 & 1.9 & 1.8 & 1.5 & 1.7 \\
\hline
\end{tabular}

Note: The dependent variable is $(\mathrm{I} / \mathrm{Y})_{\mathrm{wd}, \mathrm{t}}$. The sample period in cols. $1-4 \mathrm{i}$ 1959-88. It is $1959-72$ in col. 5 and 1973-88 in col. 6 . 
Table 4

System Regressions for World Expected Real Interest Rate and Investment Ratio

(1)

Investment Demand Ratio
(2)

Desired Saving Rate
(3)

Desired Saving Rate

Constant

0.0

$$
\begin{aligned}
& .097 \\
& (.018)
\end{aligned}
$$

0.0

.135

STOCK $_{w d, t-1}$

.051

(.010)

-.

.053

(.011)

POIL $_{\text {t- } 1}$

$$
-
$$

$-.033$

$(.006)$

--

$-.040$

.575

$(.077)$

1.0

$(.007)$

$(\mathrm{I} / \mathrm{Y})_{w d, t-1}$

1.0

$\Delta r_{w d, t}^{e}$

$-.436$

$(.126)$

$r_{w d, t}^{e}$

-.

.343
$(.069)$

$(.139)$

.-

.343
$(.069)$
.183
$(.037)$

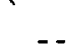

.370

(.076)

$D M_{w d, t-1}$

$-$

RDEBTY $_{w d, t-1}$

$--$

--

- -

RDEFYA $_{w d, t-1}$

Fit Statistics
$r_{w d, t}^{e}$
$(\mathrm{I} / \mathrm{Y})_{\mathrm{wd}, \mathrm{t}}$
$r_{w d, t}^{e}$
$(I / Y)_{w d, t}$

.475
$(.107)$

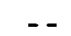

.145

$-.026$

(.015)

.144
$(.077)$

$\mathrm{R}^{2}$ (restricted) $\quad .89$

.76

.88

.78

$\hat{\sigma}$ (restricted) $\quad .0057$

.0073

.0073

$\mathrm{R}^{2}$ (unrestricted) $\quad .89$

.82

.0062

.86

$\sigma$ (unrestricted) $\quad .0054$

.0061

.89

.0057

Note: The sample period is 1959-88. The estimated coefficients apply to the model that is estimated subject to the structural restrictions. For the investment demand equation, the constant is set to 0 and the coefficient of $(\mathrm{I} / \mathrm{Y})_{\mathrm{wd}, \mathrm{t}-1}$ is set to 1 . Cols. 1 and 2 apply to a model that excludes fiscal variables; cols. 3 and 4 to a model that includes the two fiscal variables shown. The fit statistics apply to the restricted model and to an unrestricted form that relaxes the constraints from the structural model. 
Table 5

Simulated Effects on Expected Real Interest Rates and Investment Ratios (results refer to means for the periods indicated)

Actual Simulated STOCK

POIL

DM Initial Total

Conditions

I. Study period: 1981-86, reference period: 1975-80

\begin{tabular}{lrrrrrr}
$\Delta \mathrm{r}_{\text {wd, }}^{\mathrm{e}}$ & .039 & .038 & .025 & .019 & .003 & -.009 \\
$\Delta(\mathrm{I} / \mathrm{Y})_{\text {wd }, \mathrm{t}}$ & -.011 & -.009 & .014 & -.009 & -.002 & -.012 \\
& \multicolumn{5}{c}{ Unrestricted Model } \\
$\Delta \mathrm{r}_{\text {wd, } \mathrm{e}}^{\mathrm{N}}$ & .039 & .031 & .021 & .014 & .005 & -.009 \\
$\Delta(\mathrm{I} / \mathrm{Y})_{\text {wd }, \mathrm{t}}$ & -.011 & -.015 & .012 & -.015 & -.001 & -.011
\end{tabular}

II. Study period: 1975-80, reference period: 1965-70

Restricted model

$\begin{array}{lrrrrrr}\Delta \mathrm{r}_{\text {Wd,t }}^{\mathrm{e}} & -.022 & -.013 & -.018 & .011 & -.007 & .001 \\ \Delta(\mathrm{I} / \mathrm{Y})_{\text {Wd }, \mathrm{t}} & -.015 & -.010 & -.011 & -.005 & .003 & .003\end{array}$

Unrestricted model

$\begin{array}{lrrrrrr}\Delta \mathrm{r}_{\mathrm{wd}, \mathrm{t}}^{\mathrm{e}} & -.022 & -.011 & -.015 & .009 & -.008 & .003 \\ \Delta(\mathrm{I} / \mathrm{Y})_{\mathrm{Wd}, \mathrm{t}} & -.015 & -.010 & -.008 & -.008 & .001 & .005\end{array}$

III. Study period: 1987-88, reference period: 1985-86

Restricted model

$\begin{array}{lrrrrrr}\Delta \mathrm{r}_{\mathrm{wd}, \mathrm{t}}^{\mathrm{e}} & -.017 & -.021 & .002 & -.019 & -.001 & -.003 \\ \Delta(\mathrm{I} / \mathrm{Y})_{\mathrm{Hd}, \mathrm{t}} & .011 & .009 & .002 & .008 & .001 & -.002\end{array}$

Unrestricted model

$\begin{array}{lrrrrrr}\Delta \mathrm{r}_{\mathrm{wd}, \mathrm{t}}^{\mathrm{e}} & -.017 & -.020 & .002 & -.017 & -.002 & -.003 \\ \Delta(\mathrm{I} / \mathrm{Y})_{\mathrm{wd}, \mathrm{t}} & .011 & .010 & .001 & .009 & .000 & -.001\end{array}$


Table 5 , continued

Actual Simulated
Total STOCK POIL $\quad$ DM $\quad \begin{gathered}\text { Initial } \\ \text { Conditions }\end{gathered}$

IV. Study period: 1989, reference period: 1988

Restricted model

$\begin{array}{lcccrrr}\Delta \mathrm{r}_{w d, \mathrm{t}}^{\mathrm{e}} & .011 & .014 & .015 & -.005 & -.003 & .007 \\ \Delta(\mathrm{I} / \mathrm{Y})_{w d, \mathrm{t}} & -- & .017 & .005 & .002 & .001 & .009\end{array}$

Unrestricted model

$\begin{array}{lcrrrrr}\Delta \mathrm{r}_{\mathrm{wd}, \mathrm{t}}^{\mathrm{e}} & .011 & .013 & .015 & -.004 & -.003 & .006 \\ \Delta(\mathrm{I} / \mathrm{Y})_{w d, \mathrm{t}} & -- & .019 & .008 & .002 & .000 & .009\end{array}$

\begin{tabular}{|c|c|c|c|c|c|c|c|}
\hline Period & $r_{w d, t}^{e}$ & $(\mathrm{I} / \mathrm{Y})_{\mathrm{wd}, \mathrm{t}}$ & $\begin{array}{l}\text { s of Variable } \\
\text { STOCK }_{w d, t-1}\end{array}$ & $\mathrm{POIL}_{\mathrm{t}-1}$ & $D M_{w d, t-1}$ & $r_{\text {wd,t- } 1}^{e^{\text {Initial }}}$ & $\begin{array}{l}\text { Conditions } \\
\left(\mathrm{I} / \mathrm{Y}^{\mathrm{r}}\right)_{\text {wd,t- }}\end{array}$ \\
\hline $\begin{array}{l}1989 \\
1988\end{array}$ & $\begin{array}{l}.0347 \\
.0233\end{array}$ & $\begin{array}{c}(.247) \\
.242\end{array}$ & $\begin{array}{r}.1484 \\
-.0817\end{array}$ & $\begin{array}{l}.406 \\
.519\end{array}$ & $\begin{array}{l}.0661 \\
.0541\end{array}$ & $\begin{array}{l}.0233 \\
.0225\end{array}$ & $\begin{array}{l}.242 \\
.230\end{array}$ \\
\hline $\begin{array}{l}1987-88 \\
1985-86\end{array}$ & $\begin{array}{l}.0229 \\
.0395\end{array}$ & $\begin{array}{l}.236 \\
.225\end{array}$ & $\begin{array}{l}.0847 \\
.1370\end{array}$ & $\begin{array}{l}.470 \\
.839\end{array}$ & $\begin{array}{l}.0895 \\
.0906\end{array}$ & $\begin{array}{l}.0401 \\
.0443\end{array}$ & $\begin{array}{l}.225 \\
.226\end{array}$ \\
\hline $\begin{array}{l}1981-86 \\
1975-80 \\
1965-70\end{array}$ & $\begin{array}{l}.0424 \\
.0031 \\
.0247\end{array}$ & $\begin{array}{l}.219 \\
.230 \\
.245\end{array}$ & $\begin{array}{r}.0769 \\
-.0624 \\
.0092\end{array}$ & $\begin{array}{l}.927 \\
.610 \\
.407\end{array}$ & $\begin{array}{l}.0791 \\
.0880 \\
.0677\end{array}$ & $\begin{array}{l}.0245 \\
.0061 \\
.0219\end{array}$ & $\begin{array}{l}.226 \\
.249 \\
.238\end{array}$ \\
\hline
\end{tabular}

Note: The column labeled "simulated total" refers to the change in the average simulated value of $r_{\mathrm{wd}, t}^{e}$ or $(I / Y)_{\mathrm{wd}, t}$ from the reference period to the study period. These dynamic simulations use the actual values of STOCK $_{w d, t-1}$, POIL $_{t-1}$, and $D M_{w d, t-1}$, and the actual initial values of $r_{w d, t-1}^{e}$ and $(\mathrm{I} / \mathrm{Y})_{\mathrm{wd}, \mathrm{t}-1}$ at the beginnings of the reference and study periods. The column labeled "STOCK" shows the part of the change in the simulated values that is attributable to differences in the time series of STOCK $w d, t-1$ for the study and reference periods. The other columns give the corresponding information for differences in the time series of $\mathrm{POIL}_{t-1}$, DM $w, t-1$, and the values for $r_{w d, t-1}^{e}$ and $(I / Y)_{w d, t-1}$ at the start of the study and reference periods. The value of $(I / Y)_{w d, t}$ for 1989 is based on incomplete data. 
Table 6

Nine-Country Systems for Expected Real Interest Rates

(1) (2) (3) (4) (5) (6)

(i)

\begin{tabular}{|c|c|c|c|c|c|c|c|}
\hline Constant & separate & separate & separate & $\begin{array}{l}-.087 \\
(.020)\end{array}$ & separate & separate & separate \\
\hline STOCK $_{w d, t-1}$ & $\begin{array}{l}.048 \\
(.006)\end{array}$ & $\begin{array}{l}.052 \\
(.007)\end{array}$ & $\cdots$ & $\begin{array}{l}.040 \\
(.007)\end{array}$ & $\begin{array}{l}.049 \\
(.006)\end{array}$ & $\begin{array}{l}.048 \\
(.006)\end{array}$ & $\begin{array}{l}.032 \\
(.006)\end{array}$ \\
\hline $\mathrm{POIL}_{\mathrm{t}-1}$ & $\begin{array}{l}.043 \\
(.005)\end{array}$ & $\begin{array}{l}.043 \\
(.005)\end{array}$ & $\begin{array}{l}.030 \\
(.006)\end{array}$ & $\begin{array}{l}.034 \\
(.005)\end{array}$ & $\begin{array}{l}.049 \\
(.005)\end{array}$ & $\begin{array}{l}.044 \\
(.005)\end{array}$ & $(.071)$ \\
\hline$(\mathrm{I} / \mathrm{Y})_{w d, t-1}$ & $\begin{array}{l}.521 \\
(.080)\end{array}$ & $\begin{array}{l}.505 \\
(.087)\end{array}$ & -- & $\begin{array}{l}.408 \\
(.084)\end{array}$ & $\begin{array}{l}.447 \\
(.095)\end{array}$ & $\begin{array}{l}.549 \\
(.098)\end{array}$ & $\begin{array}{l}.575 \\
(.083)\end{array}$ \\
\hline$r_{i, t-1}^{e}$ & $\begin{array}{l}.484 \\
(.041)\end{array}$ & $\begin{array}{l}.500 \\
(.042)\end{array}$ & $\begin{array}{l}.515 \\
(.048)\end{array}$ & $\begin{array}{l}.651 \\
(.036)\end{array}$ & $\begin{array}{l}.458 \\
(.042)\end{array}$ & $\begin{array}{l}.476 \\
(.044)\end{array}$ & $\begin{array}{l}.352 \\
(.036)\end{array}$ \\
\hline$D M_{w d, t-1}$ & $\begin{array}{l}-.245 \\
(.035)\end{array}$ & $\begin{array}{l}-.255 \\
(.038)\end{array}$ & - & $\begin{array}{l}-.225 \\
(.037)\end{array}$ & $\begin{array}{l}-.161 \\
(.044)\end{array}$ & $\begin{array}{l}-.231 \\
(.040)\end{array}$ & $\begin{array}{l}-.146 \\
(.036)\end{array}$ \\
\hline STOCK $_{i, t-1}$ & -- & $\begin{array}{l}-.005 \\
(.004)\end{array}$ & $\begin{array}{l}-.004 \\
(.004)\end{array}$ & - - & -- & -- & -- \\
\hline$(\mathrm{I} / \mathrm{Y})_{\mathrm{i}, \mathrm{t}-1}$ & $\cdots$ & $\begin{array}{l}.009 \\
(.027)\end{array}$ & $\begin{array}{l}.023 \\
(.026)\end{array}$ & -- & -- & -- & - \\
\hline$D M_{i, t-1}$ & -- & $\begin{array}{l}.027 \\
(.013)\end{array}$ & $\begin{array}{l}.016 \\
(.013)\end{array}$ & -- & -- & -- & -- \\
\hline RDEBTY $_{w d, t-1}$ & -- & -- & $-\cdot$ & -- & $\begin{array}{l}.016 \\
(.014)\end{array}$ & $\begin{array}{l}.008 \\
(.015)\end{array}$ & -- \\
\hline $\mathrm{RDEFY}_{w d, t} \mathrm{t}-1$ & -- & $\cdots$ & - & $\cdots$ & $\begin{array}{l}-.231 \\
(.074)\end{array}$ & -- & -- \\
\hline RDEFYA $_{w d, t-1}$ & $\cdots$ & -- & -- & - & $\cdots$ & $\begin{array}{l}-.061 \\
(.090)\end{array}$ & $\cdots$ \\
\hline$\pi_{\mathrm{it}}^{\mathrm{e}}$ & -- & -. & -- & -- & -- & - & $\begin{array}{l}.562 \\
(.034)\end{array}$ \\
\hline
\end{tabular}

Note: The sample period is $1959-88$. The dependent variables in cols. 1-6 are $r_{i t}^{e}$ for nine countries. In col. 7 the dependent variables are the nominal interest rates, $R_{i t}$. 
Table 7

Statistics for Nine-Country System for $r_{w d, t}^{e}$

(1)
(3)
(4)
(5)

(6)

Table 6, col.1 Own coeffs on 4 world regression

\section{Country} variables $\& \mathrm{r}_{\mathrm{i}, \mathrm{t}-1}^{\mathrm{e}}$

$$
\mathrm{R}^{2} \quad \hat{\sigma}
$$$$
\begin{gathered}
-2 \cdot \log \lambda \\
(5 \%=11.1)
\end{gathered}
$$

BE

$\mathrm{CA}$

.78

.007

.58

.014

$$
3.6
$$

24.0

.011

2.0

14.5

.016

7.5

.018

.013

5.1

.014

5.9

.026

8.3

2.7

$$
\mathrm{R}^{2}
$$
$2^{1, t-1}$

.81

.69

.74

.67

.35

.58

.76

.68

.83<smiles>[CH]1CCCCC1</smiles>

.010

$.76 \quad .010$

Own coeffs on 3 own variables

$-2 \cdot \log \lambda$
$(5 \%=7.8)$

$\begin{array}{cc}\mathrm{R}^{2} & \hat{\sigma} \\ .77 & .007 \\ .62 & .014 \\ .75 & .011 \\ .40 & .017 \\ .42 & .016 \\ .64 & .013 \\ .72 & .014 \\ .68 & .021 \\ .79 & .010\end{array}$

Note: Cols. 1 and 2 provide fit statistics for individual countries for the system regression shown in Table 6, col. 1. Cols. 3-5 deal with systems in which individual countries have separate coefficients on four world variables (STOCK, POIL, I/Y, and DM) and the lagged dependent variable. Col. 3 gives the likelihood-ratio statistic $(-2 \cdot \log [1$ ikelihood ratio]) when these individual coefficients are introduced one country at a time. Cols. 4 and 5 give $f$ it statistics for each country in a system where all countries have individual coefficients on the five variables noted above. Cols. 6-8 deal with systems in which individual countries have separate coefficients on three own-country variables (STOCK, $I / Y$, and $D M$ ), each expressed as a deviation from the corresponding world variable. Col. 6 gives the likel ihood-ratio statistic when these individual coefficients are introduced one country at a time. Cols. 7 and 8 give fit statistics for each country in a system where all countries have individual coefficients on the three own-country variables. 
Table 8

Ten-Country Systems for Investment Ratios

(1)

(2)

\begin{tabular}{|c|c|c|}
\hline Constant & Separate & Separate \\
\hline STOCK $_{\mathrm{Hd}, \mathrm{t}-1}$ & $\begin{array}{l}.017 \\
(.008)\end{array}$ & -- \\
\hline $\mathrm{POIL}_{t-1}$ & $\begin{array}{l}-.020 \\
(.006)\end{array}$ & $\begin{array}{c}-.025 \\
(.004)\end{array}$ \\
\hline$(I / Y)_{w d, t-1}$ & $\begin{array}{l}.133 \\
(.102)\end{array}$ & - \\
\hline$r_{w d, t-1}^{e}$ & $\begin{array}{l}.045 \\
(.059)\end{array}$ & $\begin{array}{c}.063 \\
(.059)\end{array}$ \\
\hline$D M_{w d, t-1}$ & $\begin{array}{l}-.049 \\
(.042)\end{array}$ & $\cdots$ \\
\hline $\operatorname{STOCK}_{i, t-1}$ & $\begin{array}{l}.017 \\
(.003)\end{array}$ & $\begin{array}{l}.021 \\
(.003)\end{array}$ \\
\hline$(\mathrm{I} / \mathrm{Y})_{\mathrm{i}, \mathrm{t}-1}$ & $\begin{array}{l}.824 \\
(.027)\end{array}$ & $\begin{array}{l}.823 \\
(.024)\end{array}$ \\
\hline $\mathrm{DM}_{\mathrm{i}, \mathrm{t}-1}$ & $\begin{array}{l}.039 \\
(.010)\end{array}$ & $\begin{array}{c}.038 \\
(.010)\end{array}$ \\
\hline
\end{tabular}

Note: The sample period is 1959-88. The dependent variables are $(I / Y)_{\text {it }}$ for ten countries. 
Table A1

Quarterly Regressions for Inflation

\begin{tabular}{|c|c|c|c|c|c|c|c|c|c|}
\hline Country: & $\mathrm{BE}$ & $\mathrm{CA}$ & FR & GE & $\mathrm{JA}$ & $\mathrm{NE}$ & SW & UK & US \\
\hline S1 & $\begin{array}{l}.040 \\
(.028)\end{array}$ & $\begin{array}{l}.051 \\
(.036)\end{array}$ & $\begin{array}{l}.054 \\
(.034)\end{array}$ & $\begin{array}{l}.034 \\
(.015)\end{array}$ & $\begin{array}{l}.072 \\
(.045)\end{array}$ & $\begin{array}{l}.076 \\
(.032)\end{array}$ & $\begin{array}{l}.053 \\
(.109)\end{array}$ & $\begin{array}{l}.100 \\
(.058)\end{array}$ & $\begin{array}{l}.045 \\
(.057)\end{array}$ \\
\hline S2 & $\begin{array}{c}.047 \\
(.028)\end{array}$ & $\begin{array}{l}.067 \\
(.036)\end{array}$ & $\begin{array}{l}.051 \\
(.034)\end{array}$ & $\begin{array}{l}.025 \\
(.015)\end{array}$ & $\begin{array}{l}.014 \\
(.045)\end{array}$ & $\begin{array}{l}.012 \\
(.032)\end{array}$ & $\begin{array}{l}.048 \\
(.109)\end{array}$ & $\begin{array}{l}.051 \\
(.058)\end{array}$ & $\begin{array}{l}.050 \\
(.057)\end{array}$ \\
\hline S3 & $\begin{array}{l}.039 \\
(.028)\end{array}$ & $\begin{array}{l}.044 \\
(.036)\end{array}$ & $\begin{array}{l}.062 \\
(.034)\end{array}$ & $\begin{array}{l}.016 \\
(.015)\end{array}$ & $\begin{array}{l}.082 \\
(.045)\end{array}$ & $\begin{array}{l}.053 \\
(.032)\end{array}$ & $\begin{array}{l}.059 \\
(.109)\end{array}$ & $\begin{array}{l}.048 \\
(.058)\end{array}$ & $\begin{array}{l}.035 \\
(.057)\end{array}$ \\
\hline S4 & $\begin{array}{l}.047 \\
(.028)\end{array}$ & $\begin{array}{l}.044 \\
(.036)\end{array}$ & $\begin{array}{l}.066 \\
(.034)\end{array}$ & $\begin{array}{l}.052 \\
(.015)\end{array}$ & $\begin{array}{l}.024 \\
(.045)\end{array}$ & $\begin{array}{l}.026 \\
(.032)\end{array}$ & $\begin{array}{l}.075 \\
(.109)\end{array}$ & $\begin{array}{l}.065 \\
(.058)\end{array}$ & $\begin{array}{c}.029 \\
(.057)\end{array}$ \\
\hline $\operatorname{AR}(1)$ & $\begin{array}{l}.92 \\
(.07)\end{array}$ & $\begin{array}{l}.94 \\
(.07)\end{array}$ & $\begin{array}{c}.90 \\
(.10)\end{array}$ & $\begin{array}{l}.86 \\
(.13)\end{array}$ & $\begin{array}{l}.90 \\
(.16)\end{array}$ & $\begin{array}{l}.88 \\
(.30)\end{array}$ & $\begin{array}{l}.97 \\
(.14)\end{array}$ & $\begin{array}{l}.94 \\
(.09)\end{array}$ & $\begin{array}{c}.96 \\
(.08)\end{array}$ \\
\hline$M A(1)$ & $\begin{array}{l}-.58 \\
(.11)\end{array}$ & $\begin{array}{c}-.67 \\
(.11)\end{array}$ & $\begin{array}{l}. .55 \\
(.13)\end{array}$ & $\begin{array}{c}-.68 \\
(.16)\end{array}$ & $\begin{array}{c}-.70 \\
(.19)\end{array}$ & $\begin{array}{l}-.77 \\
(.31)\end{array}$ & $\begin{array}{c}-.84 \\
(.16)\end{array}$ & $\begin{array}{c}-.60 \\
(.12)\end{array}$ & $\begin{array}{c}-.69 \\
(.11)\end{array}$ \\
\hline $\mathrm{R}^{2}$ & .54 & .62 & .43 & .40 & .38 & .28 & .30 & .54 & .55 \\
\hline$\hat{\sigma}$ & .025 & .025 & .039 & .024 & .053 & .048 & .038 & .043 & .025 \\
\hline Q(4) & 1.8 & 12.5 & 4.0 & 9.4 & 3.8 & 9.3 & 4.0 & 0.1 & 5.8 \\
\hline
\end{tabular}

Note: The dependent variable is the inflation rate for each country. Each quarterly value is expressed at an annual rate. The sample period is 1952.2-1989.3. S1 is a dummy for quarter 1 (January to April), and so on. $A R(1)$ is the first-order autoregressive error term and $M A(1)$ is the firstorder moving-average error term. $Q(4)$ is the Q Statistic with 4 lags. 
Table A2

Definitions and Sources of Variables

(data are annual unless indicated otherwise)

R 3-month Treasury bill rate for January, April, July, October, except money-market rate for France and Japan, from International Financial Statistics (IFS) and OECD, Main Economic Indicators.

P Consumer price index $(1980=1.0)$, seasonally unadjusted, for January, April, July, October, from IFS.

$\pi_{t} \quad 4^{*} \log \left(\mathrm{P}_{\mathrm{t}+1} / \mathrm{P}_{\mathrm{t}}\right)$, quarterly.

r R- $x$, quarterly.

$x^{e} \quad$ Constructed measure of expected inflation, quarterly.

$r^{e} \quad R-x^{e}$, quarterly.

Y Real GDP (deflator $=1.0$ in 1980) from OECD National Accounts.

I Real gross domestic capital formation (deflator $=1.0$ in 1980 ) from OECD National Accounts.

STOCK Real rate of return on stock market. Nominal returns are computed from IFS data for December on industrial share prices. Consumer price inflation (December-to-December) was subtracted from the nominal returns to calculate the real returns.

POIL Ratio of U.S. PPI for crude petroleum to overall U.S. PPI (1982 base), from Citibase.

DM Growth rate of M1, computed from December values for M1 from IFS.

RDEBTY Ratio of end-of-year real central government debt (nominal debt at par value divided by the December CPI) to real GDP. For BE, CA, FR, $\mathrm{GE}$, IT, and $\mathrm{NE}$, the debt figures are the sum of domestic and foreign debt from IFS. For JA, the data are from Monthly Statistics of Japan; for SW, Monthly Digest of Swedish Statistics; for UK, Central Statistical Office, Annul Statistics; for US, Economic Report of the President.

RDEFY Ratio of real budget deficit to real GDP. The real budget deficit is the change in the real debt for the year. The real debt is the ratio of the nominal debt to the December consumer price index.

RDEFYA The residual from a regression of RDEFY for each country over 1958- 87 on the current and four annual lags of the growth rate of real GDP.

WTXX Share of country XX in the ten-country Summers-Heston (1988) real GDP. 


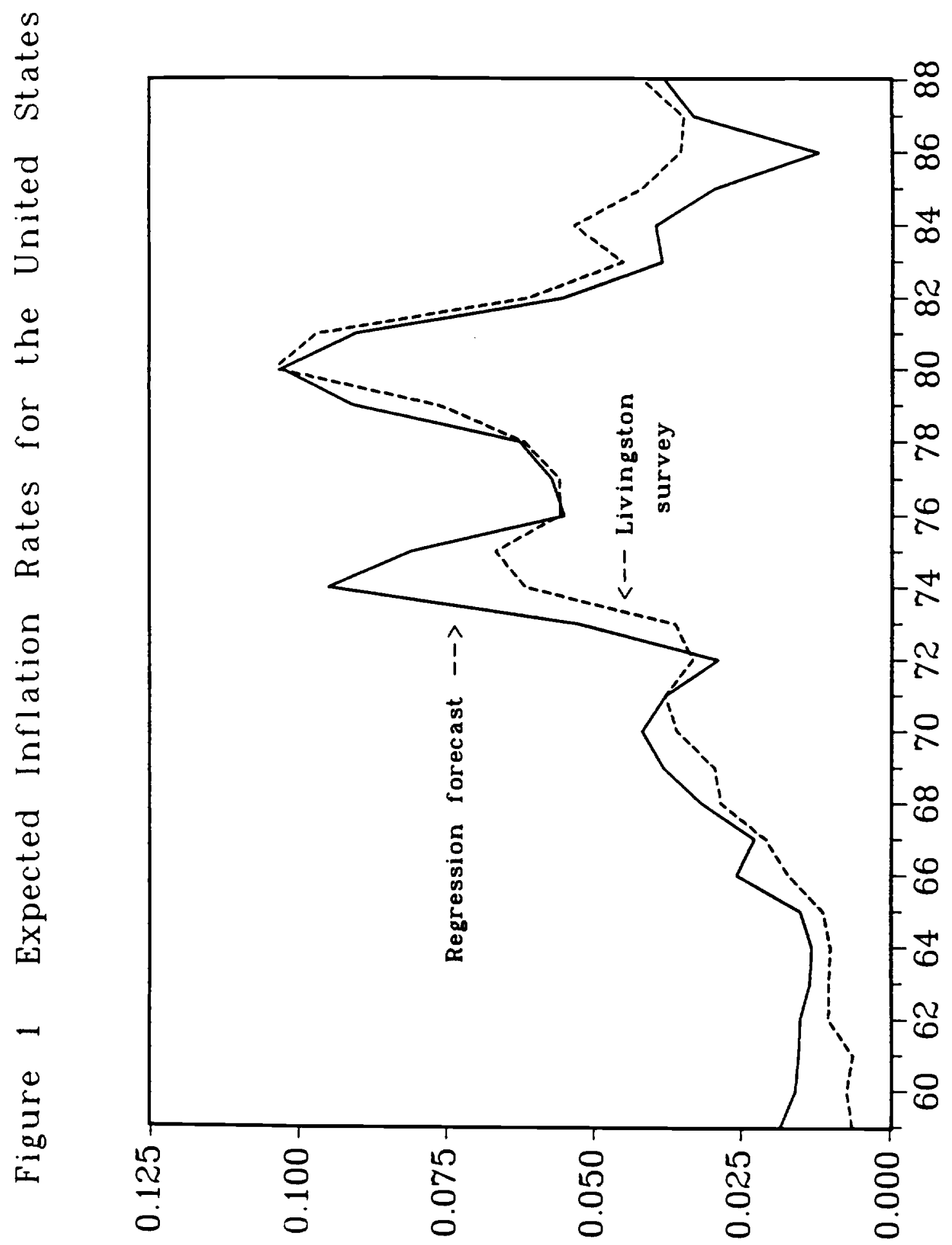




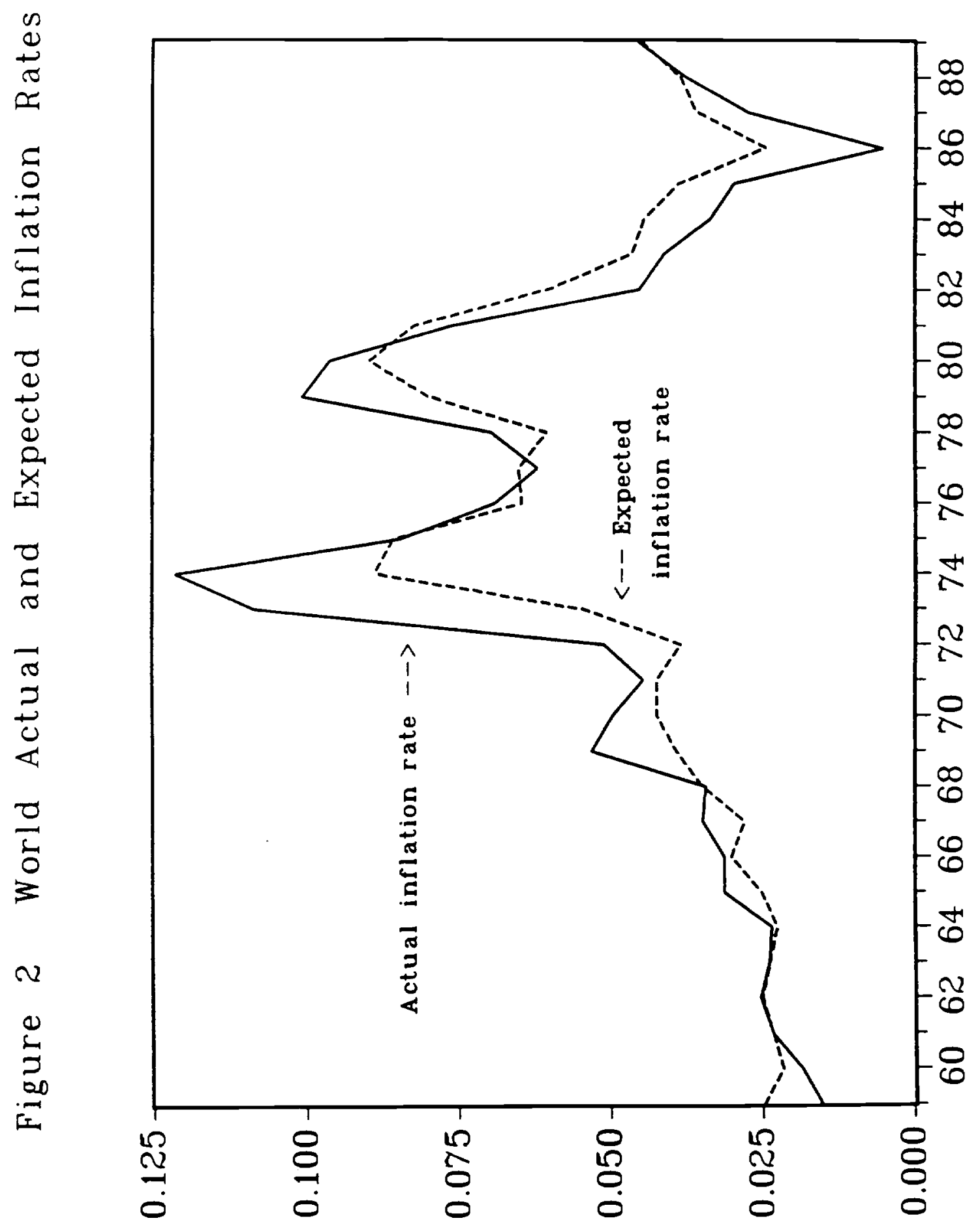




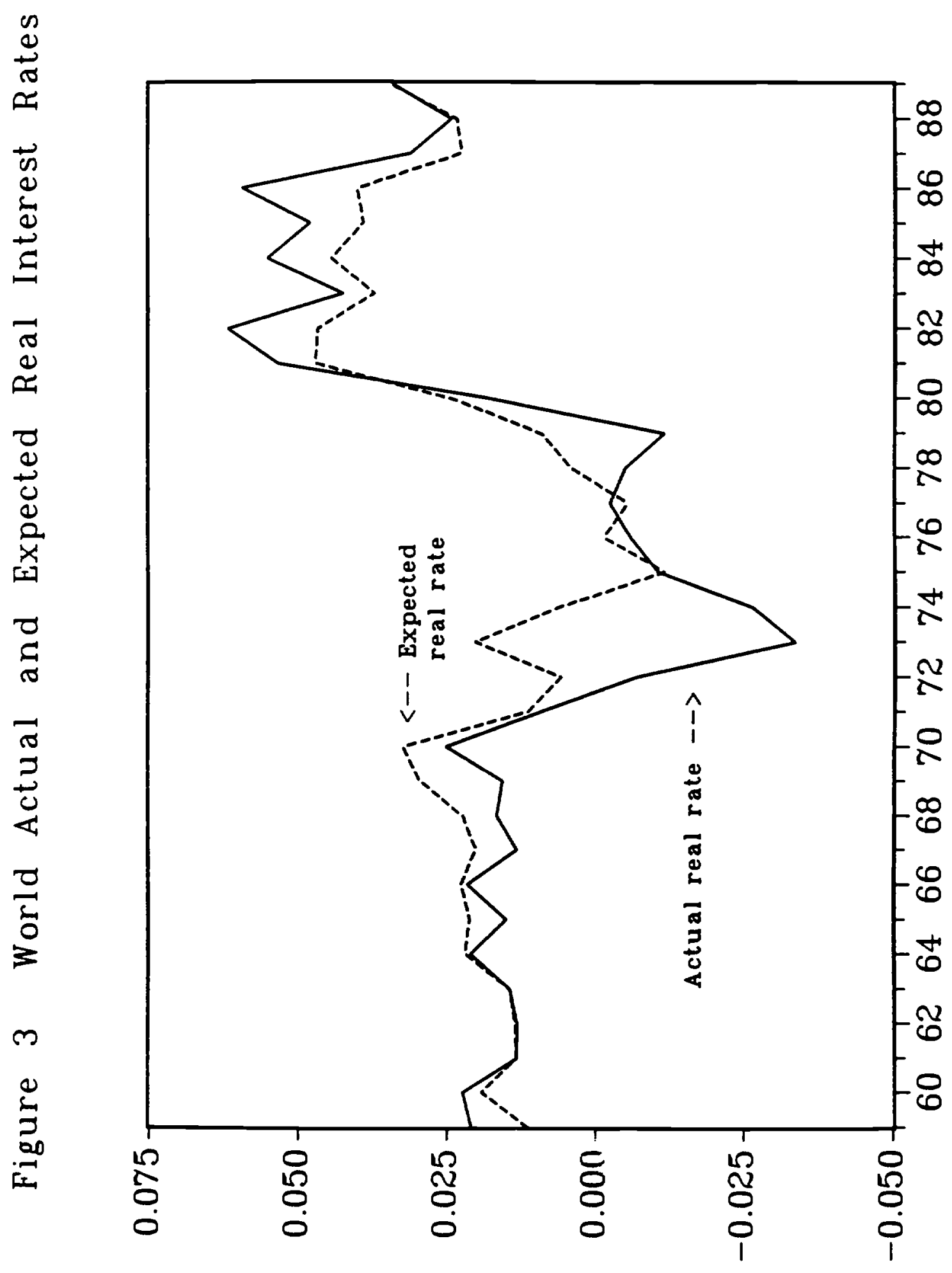




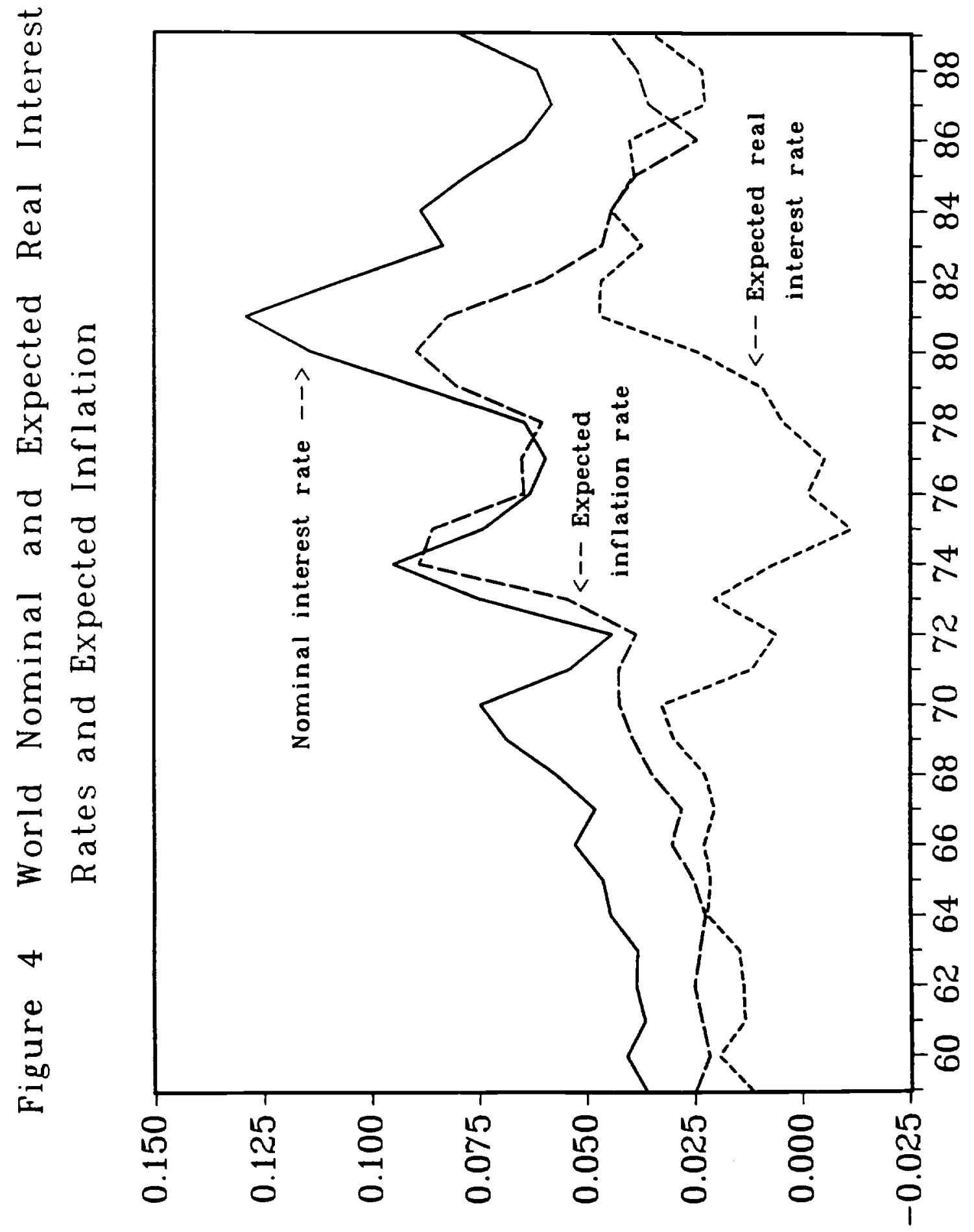




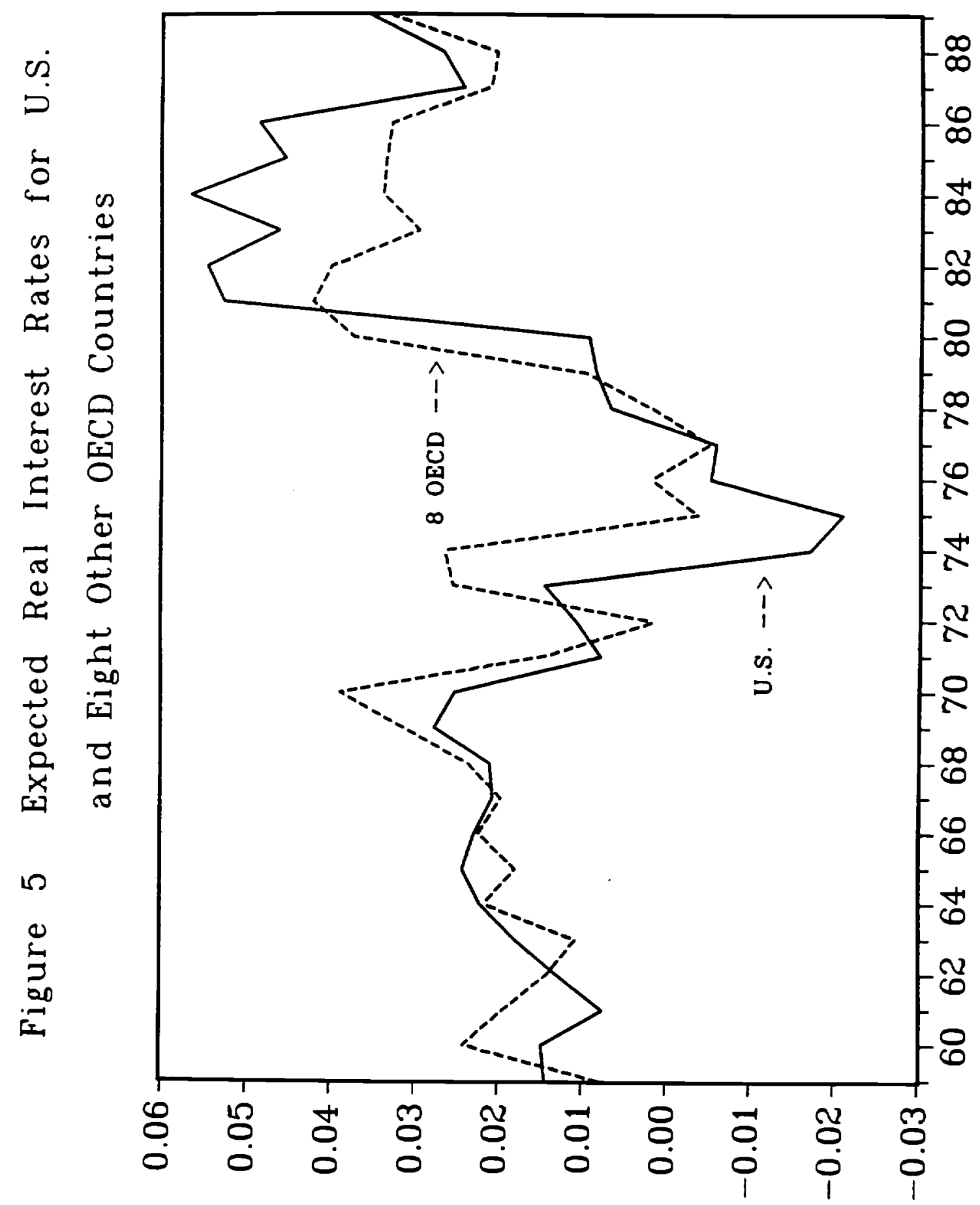




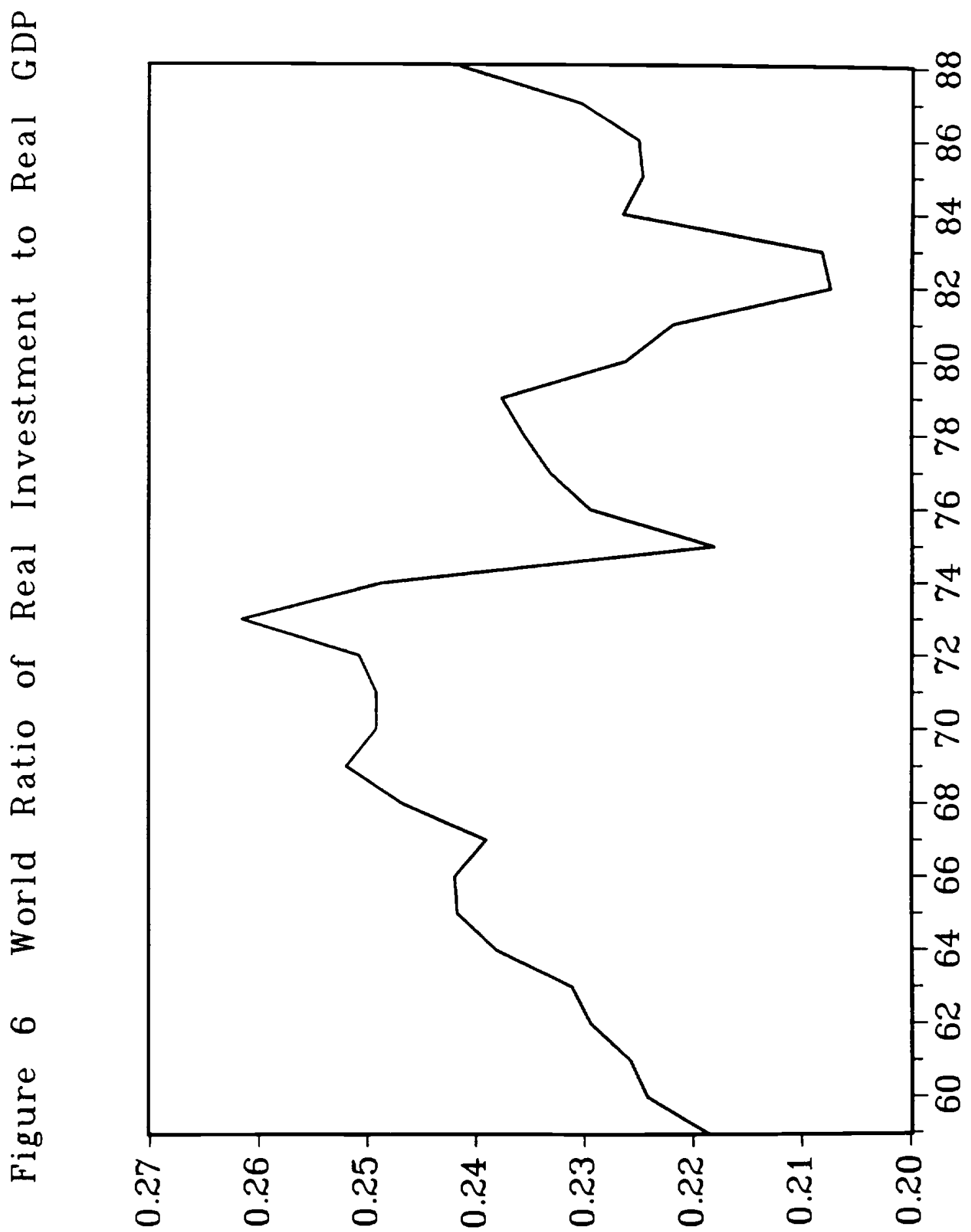




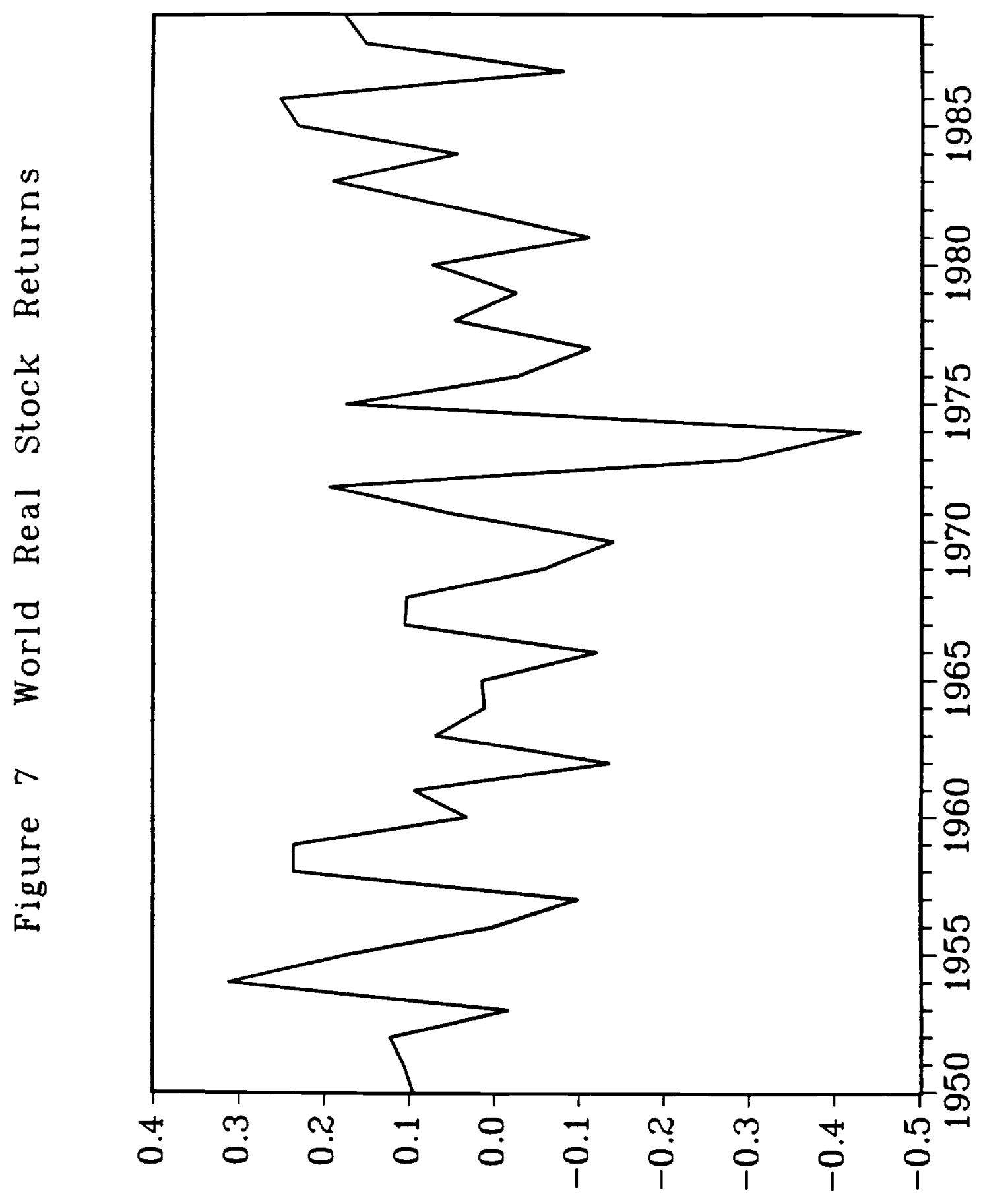




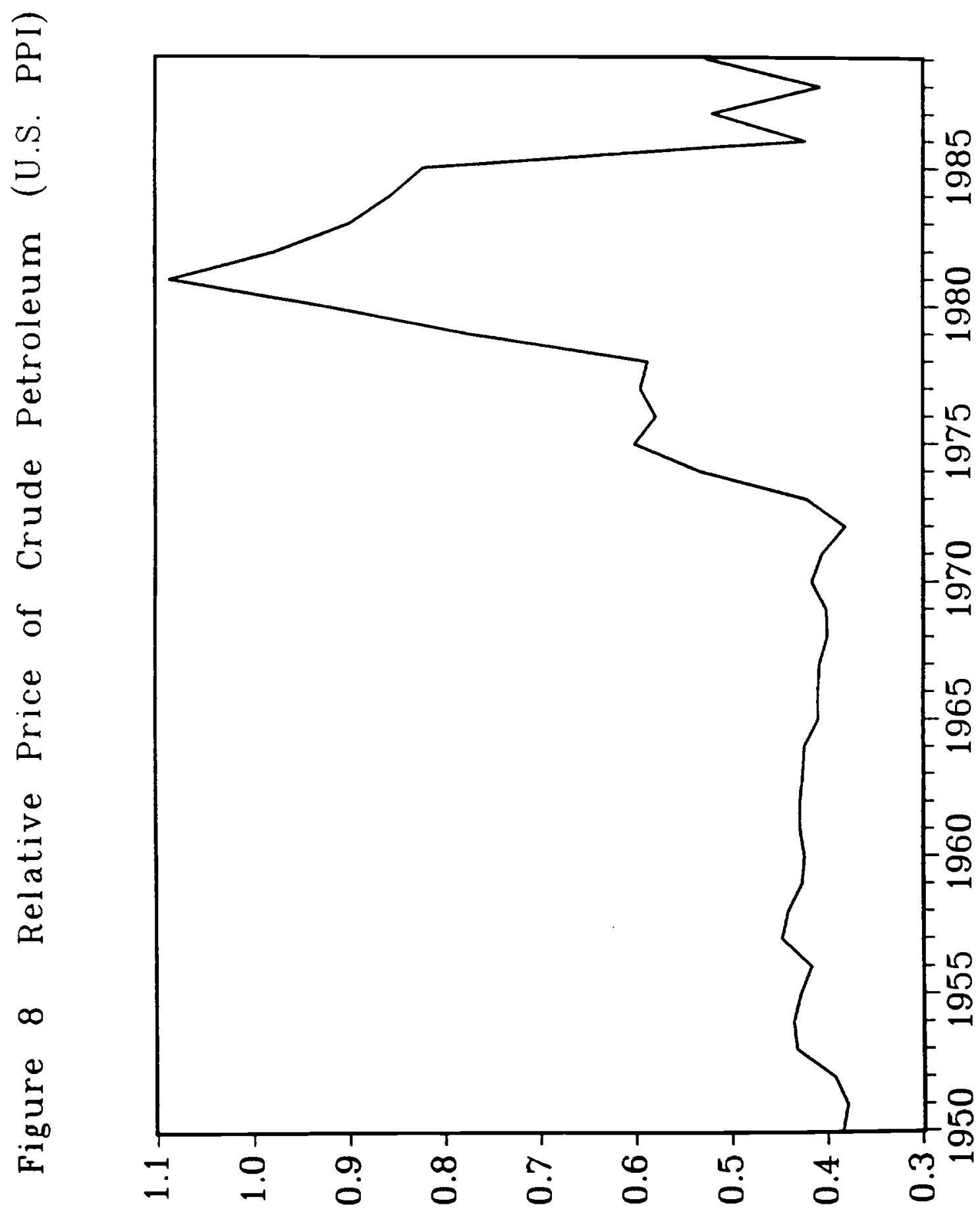




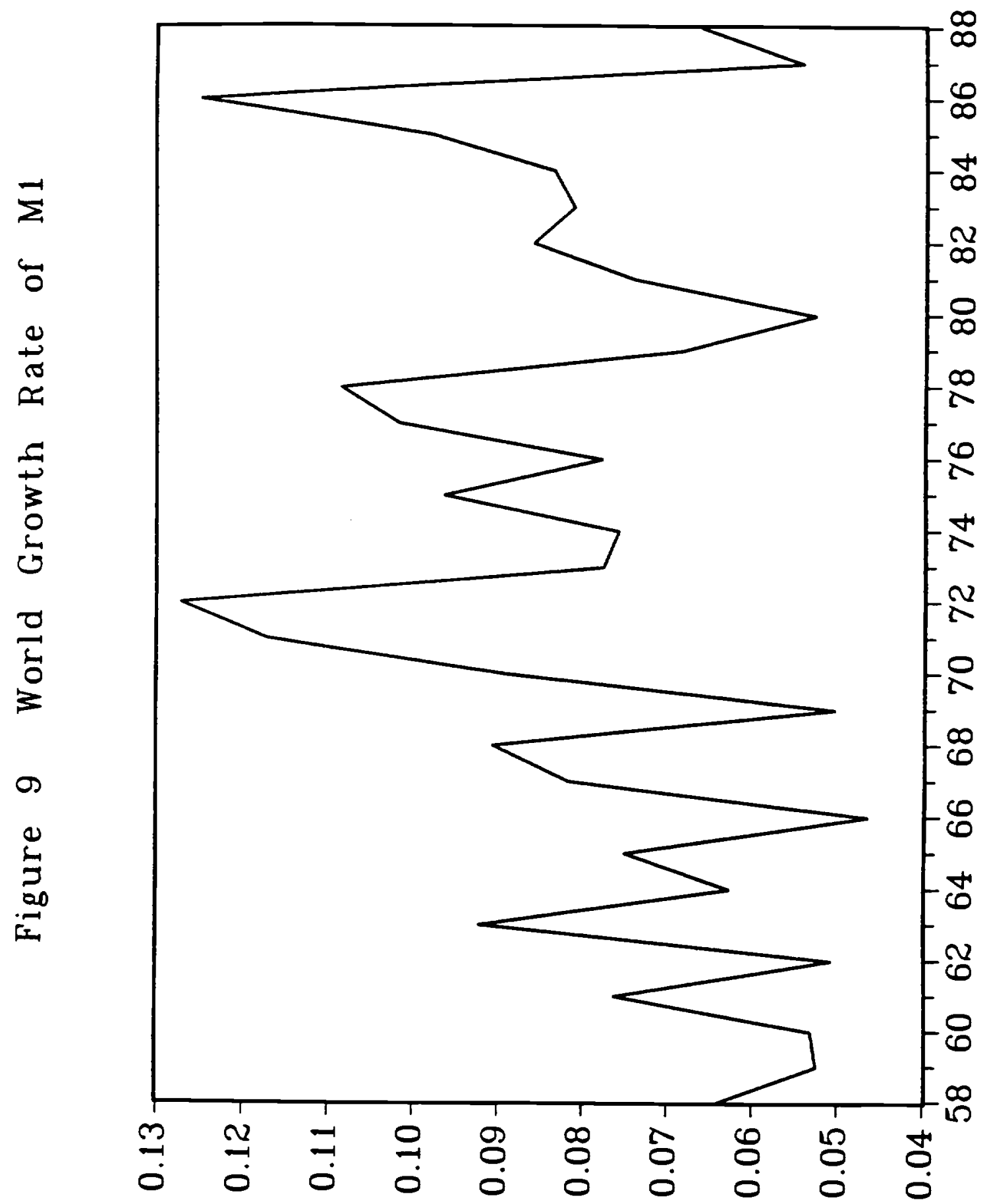




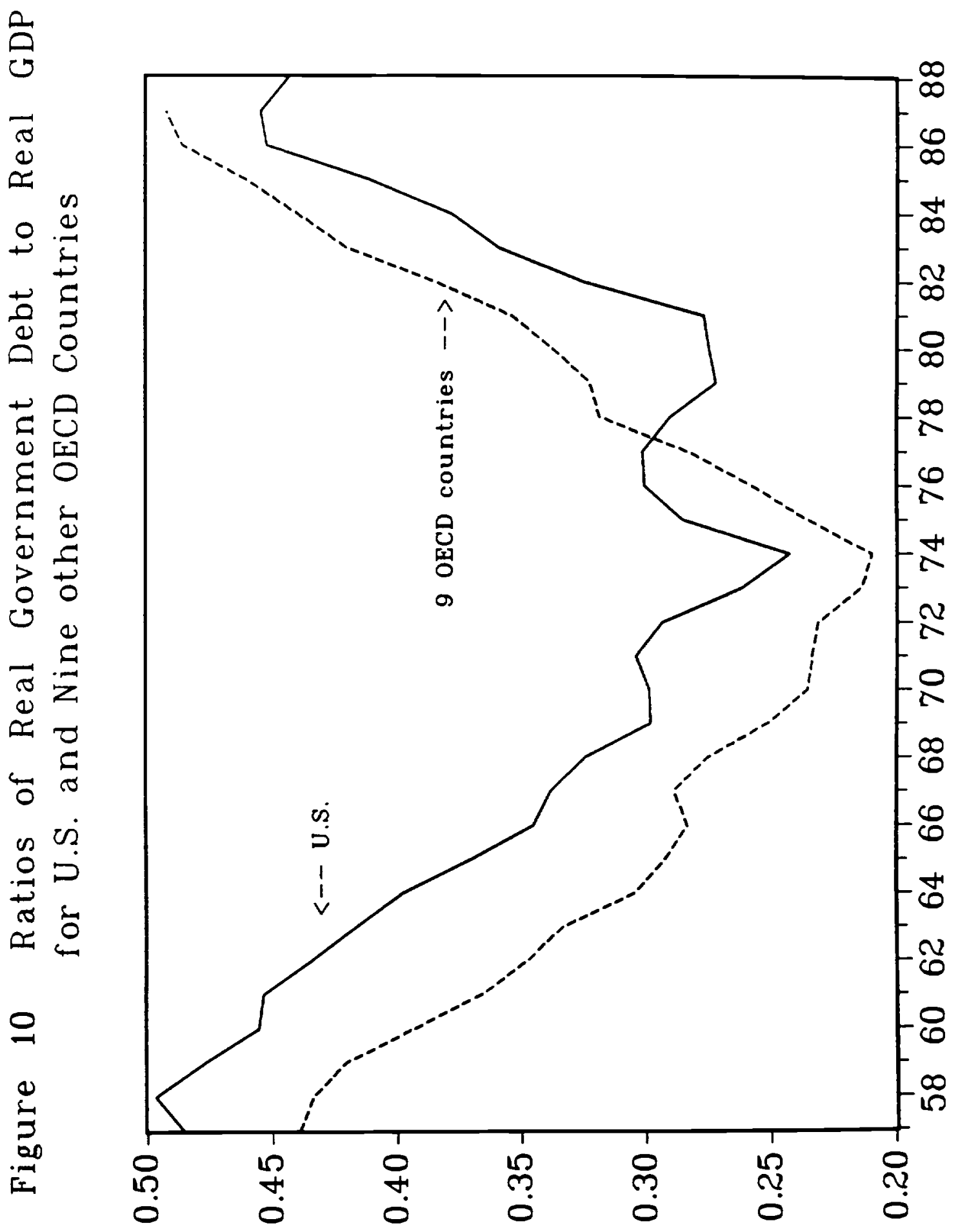




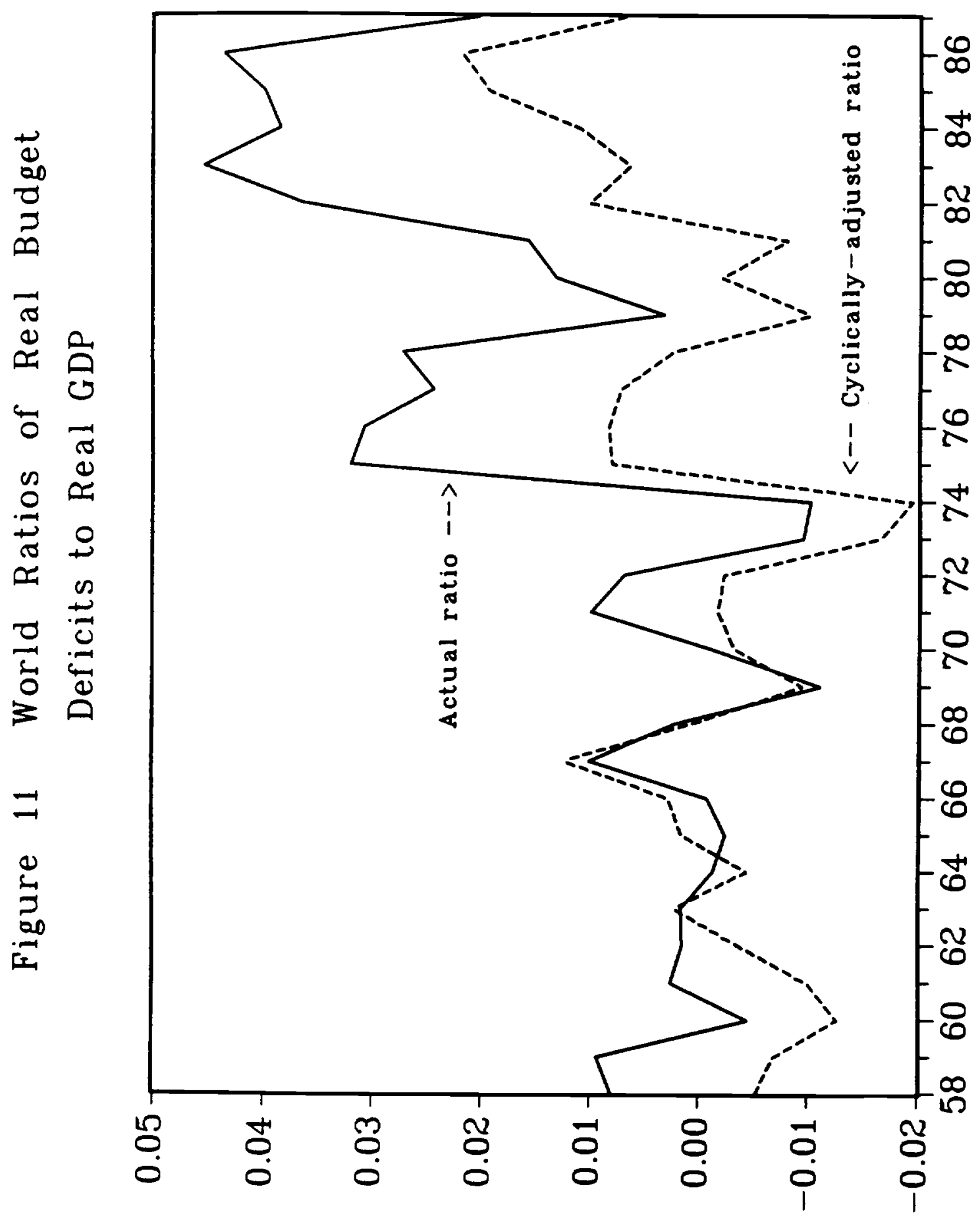




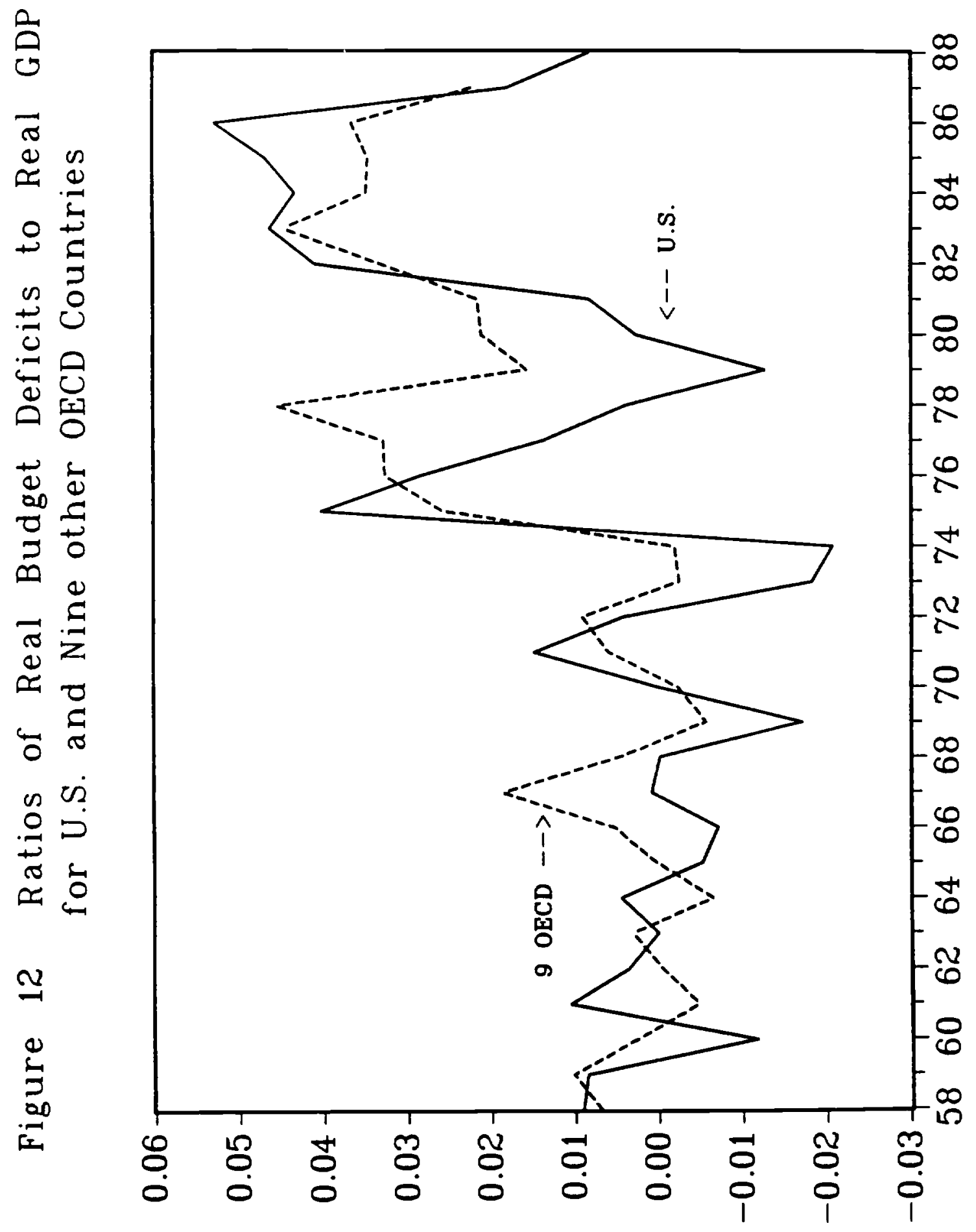




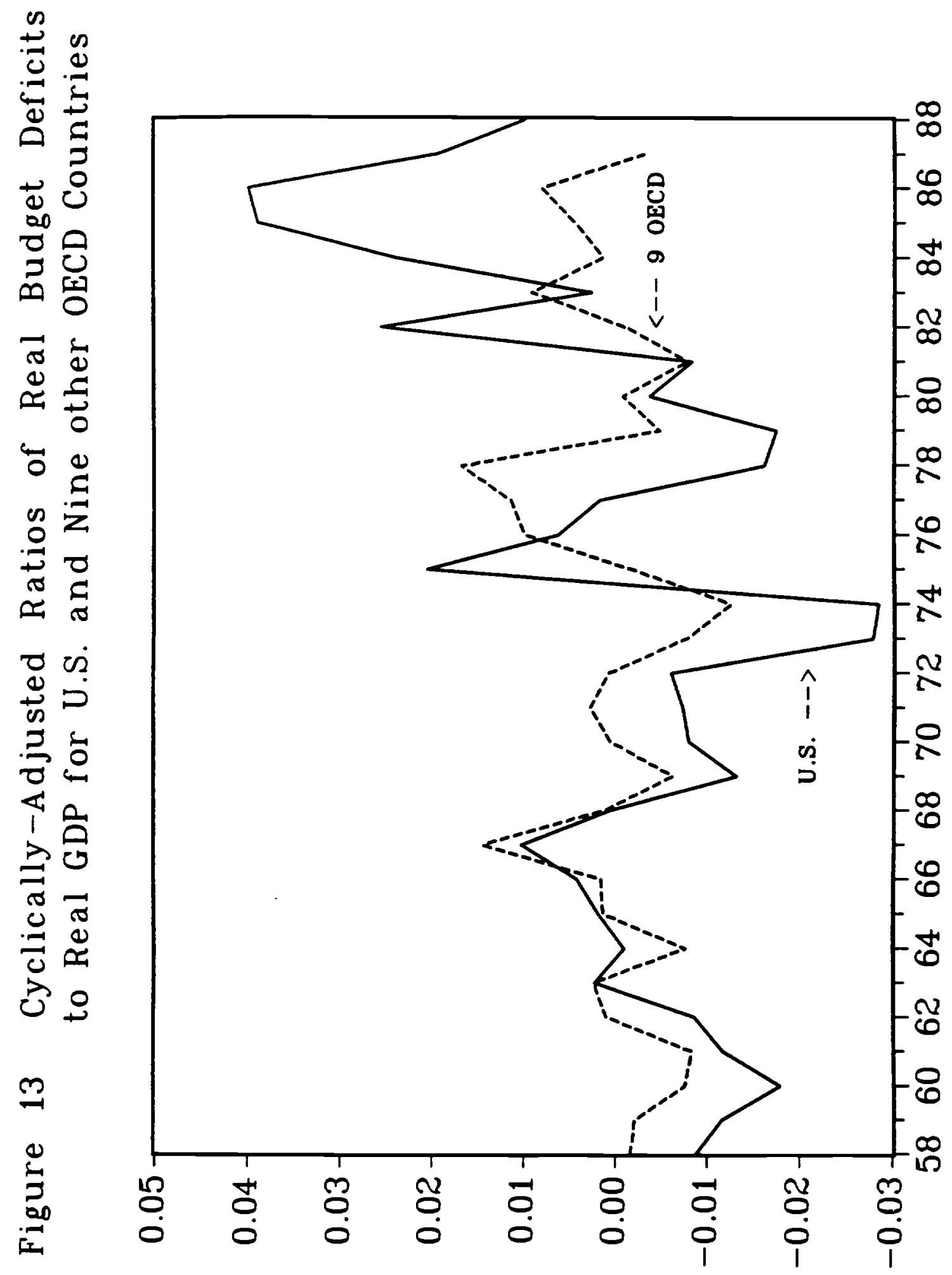




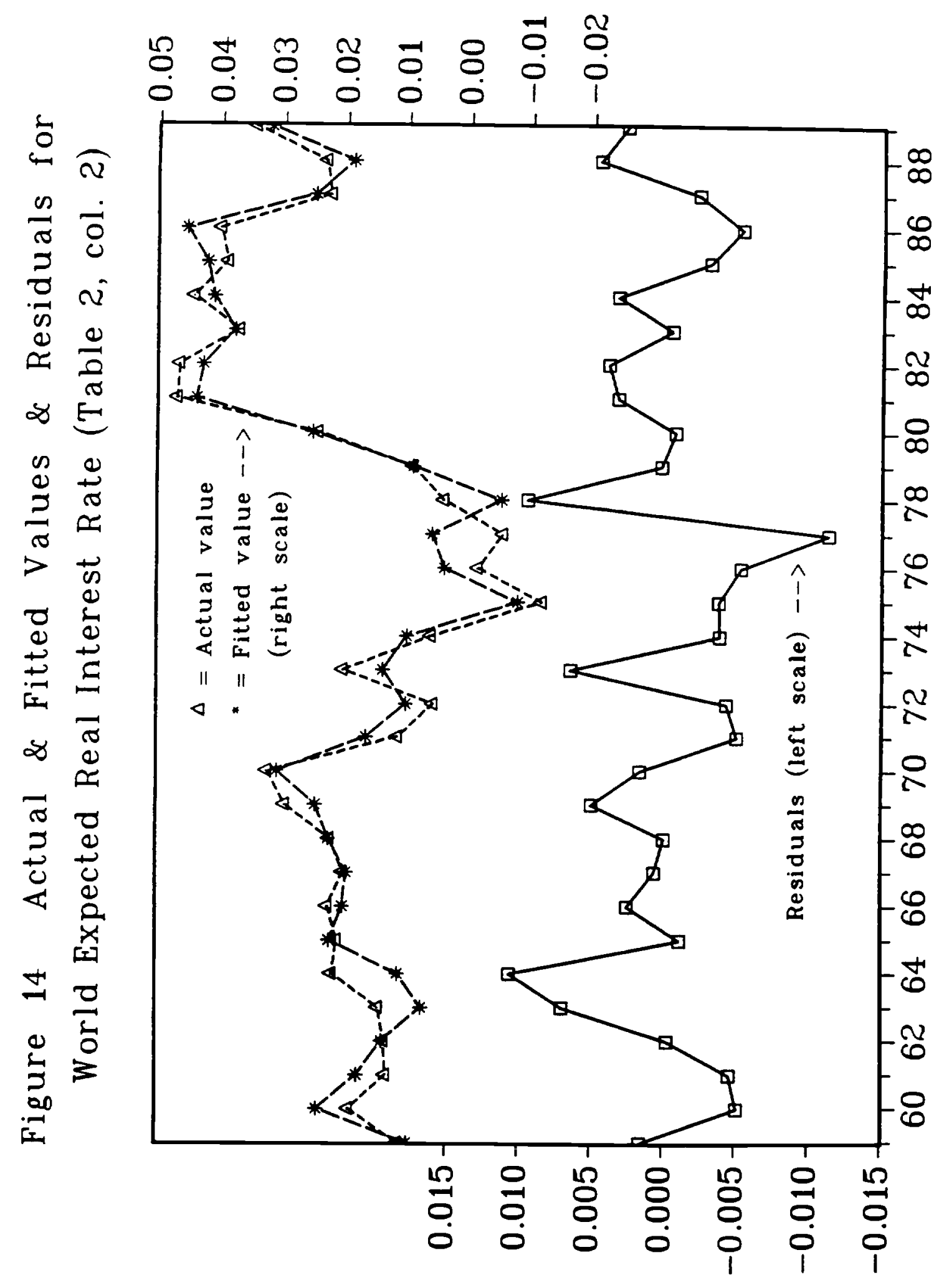




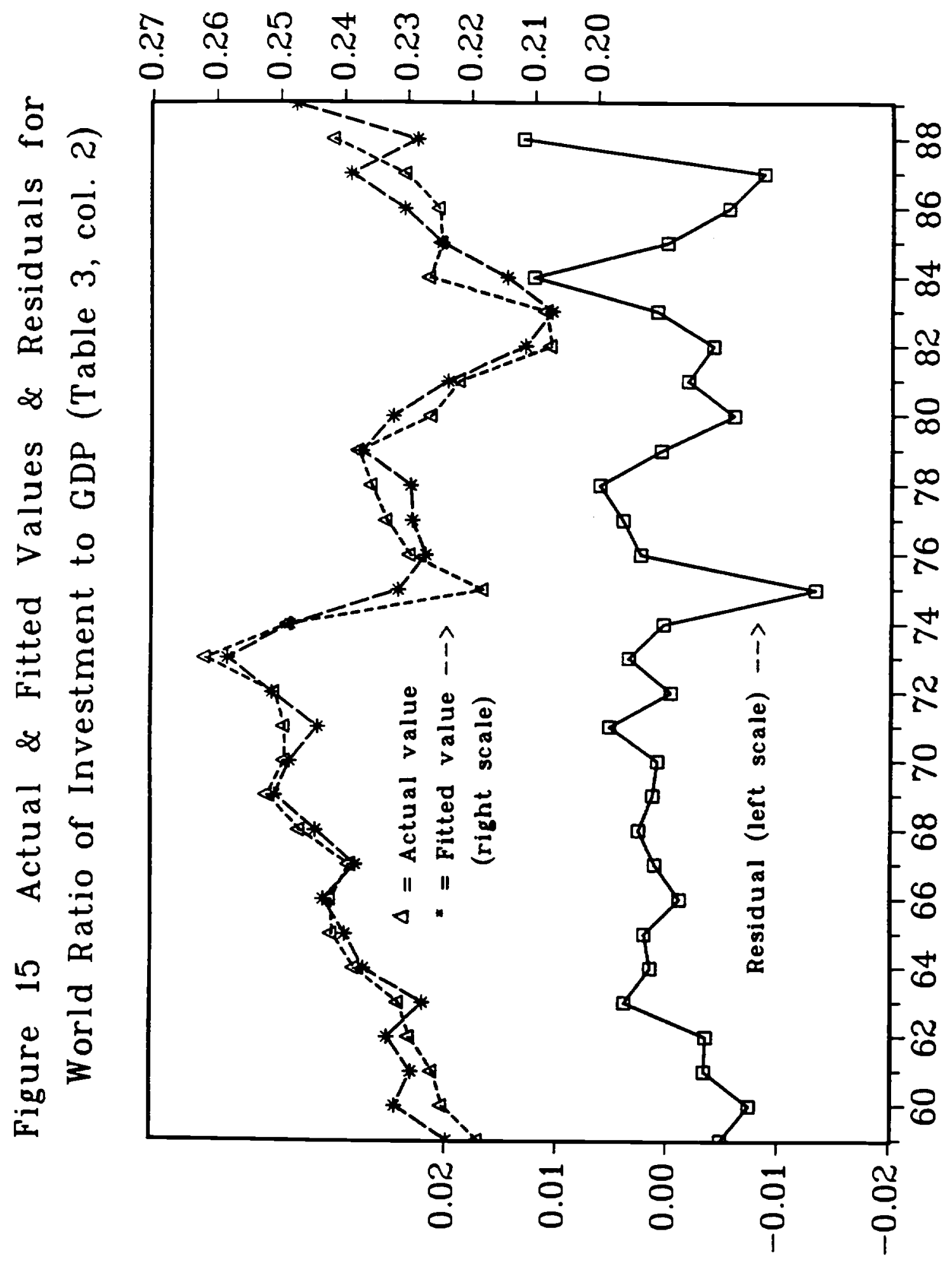

